\title{
“Comparision Between 0.2\% Ropivacaine Versus 0.2\% Ropivacaine with Dexmeditomidine In Ultrasound Guided Transversusabdominis Plane Block For Post Operative Analgesia In Unilateral Lower Abdominal Surgeries"
}

\author{
Gupta Arun Kumar ${ }^{1}, Y_{a d a v}$ Dharmendra Kumar ${ }^{2}$, Mishra L S ${ }^{3}$, \\ Mahendra Pratap ${ }^{4}$ \\ ${ }^{1}$ Associate Professor ${ }^{2}$ Lecturer.3Professorand Head4.JR, ${ }^{3}$ Department Of Anaesthesiology And Critical Care, \\ Motilal Nehru Medical College, Allahabad, Uttar Pradesh, India
}

\begin{abstract}
Background And Aims: The transversusabdominis plane block is a new rapidly expanding regional anesthesia technique that provide analgesia of Anterior abdominal wall surgeries. TransversusAbdomimis Plane block significantly reduces pain associated with lower abdominal surgeries. It may be used as primary anesthesia or Post operative analgesia.The present study aims to "Comparative study of $0.2 \%$ Ropivacaine Versus $0.2 \%$ Ropivacaine with Dexmedetomidine in Ultrasound guided TAP block for Post operative Analgesia in Unilateral lower abdominal surgeries".
\end{abstract}

Keywords: The transversusabdominis plane block,Ropivacaine,Dexmedetomidine,Unilateral lower abdominal surgeries, Ultrasound guided.

Methods: The present study on 'comparision between $0.2 \%$ Ropivacaine versus $0.2 \%$ Ropivacaine with Dexmedetomidine in ultrasound Guided TransversusAbdominis Plane Block for post operative Analgesia in Unilateral Lower Abdominal surgeries" was conducted in the Department of Anaesthesiology \& Critical Care, M.L.N. Medical college, Allahabad, U.P., India. Patient were explained the purpose of study along with the procedure and thereafter a legal valid, informed and written consent was taken from the all patient undergoing study.

Our study has total 60 patient of more than 18 years of age and ASA Class I \& II of both male and female sex divided into two groups of 30 patients each. Patients conducted under General Anaesthesia. After the completed unilateral lower abdominal surgery they were given Ultrasound Guided TransversusAbdominis Plane block for post operative analgesia.

Results: TAP block is very good for postoperative analgesia and also in the term of side effects complication. Adition of adjuant as Dexameditomidine in Ropivacaine increase the onset quality and duration of analgesia compare to Ropivacaine alone .

Conclusion: We concluded from this study that although both Ropivacaine and Ropivacaine with Dexmeditomidine in USG guided TAP block are associated with minimum haemodynamic change, haemodynamic stability are better in Ropivacaine with Dexmeditomidine. TAP block is very good for postoperative analgesia and also in the term of side effects complication. Adition of adjuant as Dexameditomidine in Ropivacaine increase the onset quality and duration of analgesia compare to Ropivacaine alone. As there are few literature available on TAP block as a sole analgesic, further studies are required to substantiate the above finding.

\section{Introduction}

The transversusabdominis plane block is a new rapidly expanding regional anesthesia technique that provide analgesia of Anterior abdominal wall surgeries. TransversusAbdomimis Plane block significantly reduces pain associated with lower abdominal surgeries. It may be used as primary anesthesia or Post operative analgesia.There are various anesthesia option for inguinal hernia repair surgery like Spinal Anaesthesia, Epidural Anaesthesia or General Anaesthesia. Pain has been found to be one of the most common cause of delayed discharge after surgery. Others being drowsiness and nausea/vomiting. Despite this overwhelming rationale for effective post operative pain control.Inguinal hernia repair is commonly performed under spinal anaesthesia sedation or general anaesthesia with an ilioinguinal/iliohypogastric nerve (INH) block or surgical field infiltration with a long-acting local anaesthetic (LA) agent ${ }^{(2)}$.General Anaesthesia may provide some benefits over Regional Anaesthesia, patient is in hemodynamic control and easy to access VAS in post operative period .The Neuraxial block Residual Analgesia may interfere with the result of study.

Epidural anesthesia is an attractive choice less hemodynamic changes are observed. But in old age patient hypotension and other hemodynamic changes are often observed as autonomic nervous system response is diminished with aging sympathetic block with epidural anesthesia cannot be controlled.

DOI: 10.9790/0853-1601042643 www.iosrjournals.org 26|Page


The abdominal surgeries may be open or laparoscopic are associated with significant post operative pain, For Post operative Analgesia various method have been used They are Paracetamol, parenteral opioids, NSAIDS, Dermal patches, patient control analgesia and epidural Analgesia.Transversusabdominis plane block is a relatively newer and novel approach of injecting local anesthesia in to the plane between the internal oblique and transversusabdominis muscle for analgesia and it was first described by Kuppuvelumaneet(1), In 1993 and was firmly documented by Rafi in 2001.Transversusabdominis plane block has been found to the safe and effective tool in variety of General,Gynecological, Urological, Plastic and Pediatric lower abdominal surgeries. USG Guided TAP block is used to approach and block the abdominal wall neural afferents. The sensory supply of the skin,muscle and parietal peritoneum of the anterior abdominal wall is derived from the anterior rami of lower six thoracic nerves and first lumbar nerve. The intercostal, subcostal, iliohypogastric, ilioinguinal course through lateral abdominal wall within the TAP before they pierce the musculature to inervate the abdomen. The TransversusAbdominis plane block can be done either pre-operative or post-operative. The procedure must be done under proper aseptic condition .

Ropivacaine is a long acting local anaesthetic drugs used widely in modern anaesthetic practice. As per Manufacturer Safety Guidelines for Infiltration Anaesthesia, high doses of Ropivacaine is safe as compared to other drugs. Prolongation of the analgesic effect and duration of block can be achieved by adding adjuvant like adrenaline, ketamine , clonidine, dexmetetomidine, etc. It was observed that adjuvant can be added to local anesthetics having pharmacodynamic and pharmacokinetic interactions with local anesthetics, it increases their efficacy, thereby increasing quality and duration of block without increasing the dose of local anaesthetic drug above safe limit .

It act by Variety of receptors mediated Nociception and peripheral sensory axons and the peripheral administration of appropriate drugs may have analgesic benefit and reduced systemic adverse effect.Post operative pain causes increased morbidity and hospital stay. Commonly used intravenous analgesics are opioids,Paracetamol, NSAIDS, and patient controlled Analgesia . Opioids used in moderate to severe pain, provide good pain control but produces various side effects Like respiratory depression, consciousness level, confusion, nausea vomiting and constipation. They are more troublesome in elderly patients. Tramadol, a weak opioid, produces lesser side effect compared to morphine, a strong opioid. Diclofenac is most commonly used NSAID useful in moderate pain but having risk of renal failure especially in elderly and dehydrated patient . Intravenous paracetamol is useful in mild to moderate pain, but have a potential hepatotoxic in overdose, should be avoided in patient with hepatic compromise.

The TransversusAbdominis plane (TAP) block is a relatively new Regional Anaesthesia technique that provides analgesia to the parietal peritoneum as well as the skin and muscles of the anterior abdominal wall. It has a high margin of safety and is technically simple to perform, especially under ultrasound guidance. TAP block can preserve bladder and lower limb motor function thereby allowing early mobilization after surgery. A growing body of evidence supports the use of TAP blocks for a variety of abdominal procedures, yet widespread adoption of this therapeutic adjunct has been slow. In part, this may be related to the limited sources for anesthesiologists to develop an application.First described just a decade ago, it has undergone several modifications, which highlighted its potential utility for an increasing array of surgical procedures. Despite a relatively low risk of complication and a high success rate using modern techniques, TransversusAbdominis Plane blocks remains overwhelmingly underutilized.

There are no literature available on comparative study between $0.2 \%$ Ropivacaine versus $0.2 \%$ Ropivacaine with $0.5 \mathrm{mg} / \mathrm{kg}$ Dexmedetomidine in Transverses Abdominis Plane block. In present study, these two drugs were compared in terms of safety, efficacy, quality and duration for unilateral lower abdominal surgery of average built patients.

\section{Material Andmethods}

The present study on 'comparision between $0.2 \%$ Ropivacaine versus $0.2 \%$ Ropivacaine with Dexmedetomidine in ultrasound Guided TransversusAbdominis Plane Block for post operative Analgesia in Unilateral Lower Abdominal surgeries", was conducted in the Department of Anaesthesiology \& Critical Care, M.L.N. Medical college, Allahabad, U.P., India. Patient were explained the purpose of study along with the procedure and thereafter a legal valid, informed and written consent was taken from the all patient undergoing study.

Our study has total 60 patient of more than 18 years of age and ASA Class I \& II of both male and female sex divided into two groups of 30 patients each. Patients conducted under General Anaesthesia. After the completed unilateral lower abdominal surgery they were given Ultrasound Guided TransversusAbdominis Plane block for post operative analgesia.

\section{The Exclusion Criteria From The Study :}

1. Patient not given consent 
2. Patient with known hypersensitivity to local anesthetic drugs.

3. Bleeding disorder

4. Uncontrolled co-morbidity like diabetic mellitus, hypersensitivity .

5. Sepsis at the site of injection .

6. Psychiatric disorder .

7. Patient having cardio-respiratory illness.

8. Patient having metabolic disorder.

9. Nervous system disorder .

10. Hypovolemia .

Routine instigations like complete blood count, urine examination, bleeding time, clotting time, chest x-ray PA view, electrocardiogram and other relevant investigations were done in all patient preoperatively .All patient were randomly allocated into two groups, 30 members in each .Group R : Patients undergoing Unilateral lower abdominal surgery is given $20 \mathrm{ml}$ Ropivacaine $0.2 \%$ with $1 \mathrm{ml}$ normal saline (total $21 \mathrm{ml}$ ) to that side through Ultrasound Guided TransversusAbdominis plane block for post operative analgesia.

Group D : Patients undergoing Unilateral lower abdominal surgery is given $20 \mathrm{ml}$ Ropivacaine $0.2 \%$ with 0.5 $\mathrm{mcg} / \mathrm{kg}$ Dexmedetomedine (total $21 \mathrm{ml}$ ) to that side in Ultrasound Guided TransversusAbdominis Plane block for post operative analgesia.

The patient were assessed thoroughly and explained about the anaesthetic procedure in preoperative room, good I.V. access secured and Intravenous Fluid started.Thereafter patient were shifted to operation theater and all monitoring devices were attached viz device measuring noninvasive blood pressure, ECG and $\mathrm{SpO}_{2}$, appropriate function of ventilator machine were assessed \& patient is prepared for General Anaesthesia. Premedication with Inj. Midazolam $0.01 \mathrm{mg} / \mathrm{kg}$ i.v.with Inj. Glycopyrrolate $0.01 \mathrm{mg} / \mathrm{kg}$ i.v.Preoxygenation for 3 minutes and then induction with Inj. Propofol $2.0 \mathrm{mg} / \mathrm{kg}$ i.v. is done.After induction, patient is given muscle relaxant Succinylcholine $2 \mathrm{mg} / \mathrm{kg}$ iv to obtain ideal intubating condition and patient is intubated with cuffed endotracheal tube, position of the tube is confirmed with auscultation \& tube is fixed. Intermittent positive pressure ventilation is started \& loading dose of non-depolarising muscle relaxant vecuronium $(0.05 \mathrm{mg} / \mathrm{kg})$ i.v. is given.

Anaesthesia is maintained with Oxygen and Nitrous oxide with inhalational anaesthetic agent (Isoflurane) and long acting Non-depolarising type muscle relaxant Vecuronium $(0.01 \mathrm{mg} / \mathrm{kg})$.During intraoperative period ,patient received $10 \mathrm{mg}$ ondensetran for postoperative nausea and vomiting. After completion of surgery, patient is reversed with appropriate dose of Neostigmine $(0.05 \mathrm{mg} / \mathrm{kg})$ with Glycopyrrolate $(0.01 \mathrm{mg} / \mathrm{kg})$ i.v. after thorough suctioning of oral cavity. Patient is extubated after complete reversal of patient.In Group R, patient is placed in lateral position, cleaning \& draping is done and under all aseptic conditions, the ultrasound guided (SonoSite, micromaxx) transversusabdominis plane block is given.
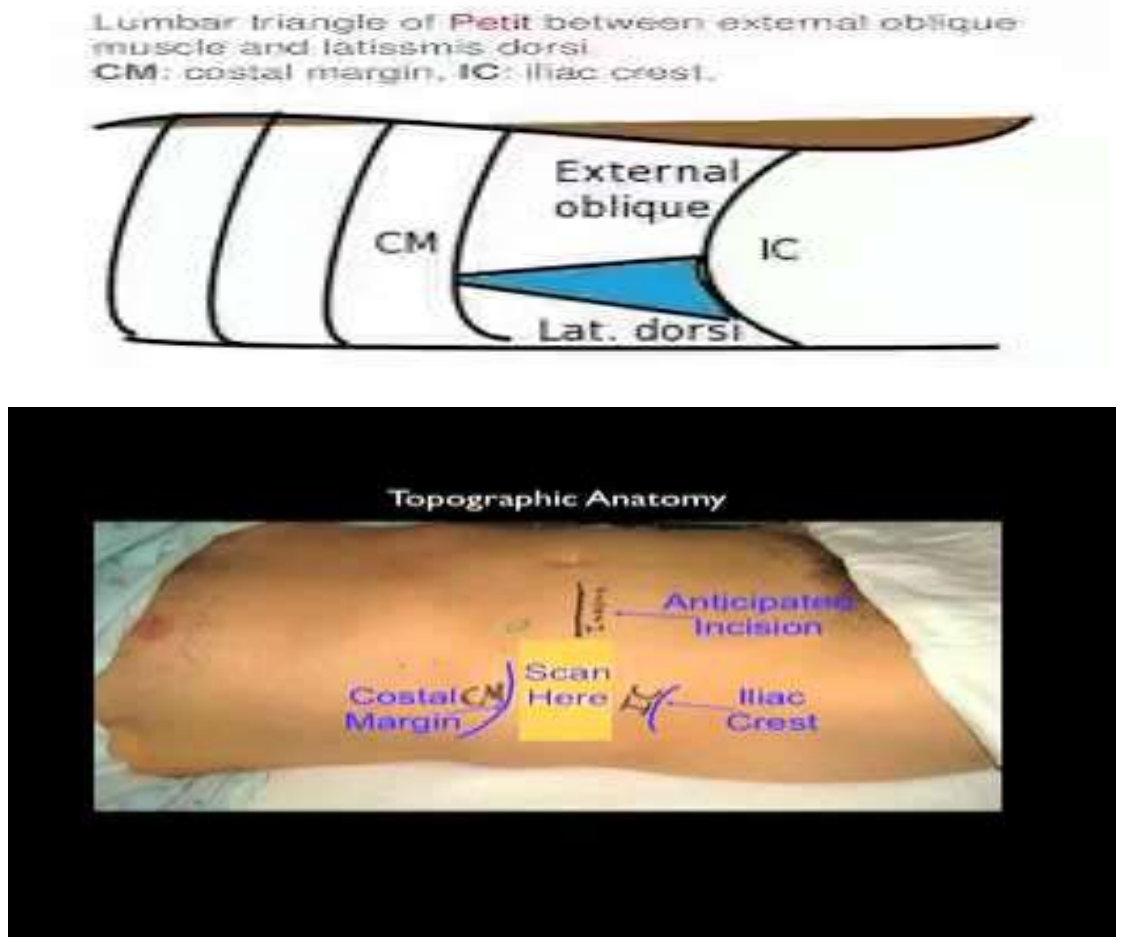

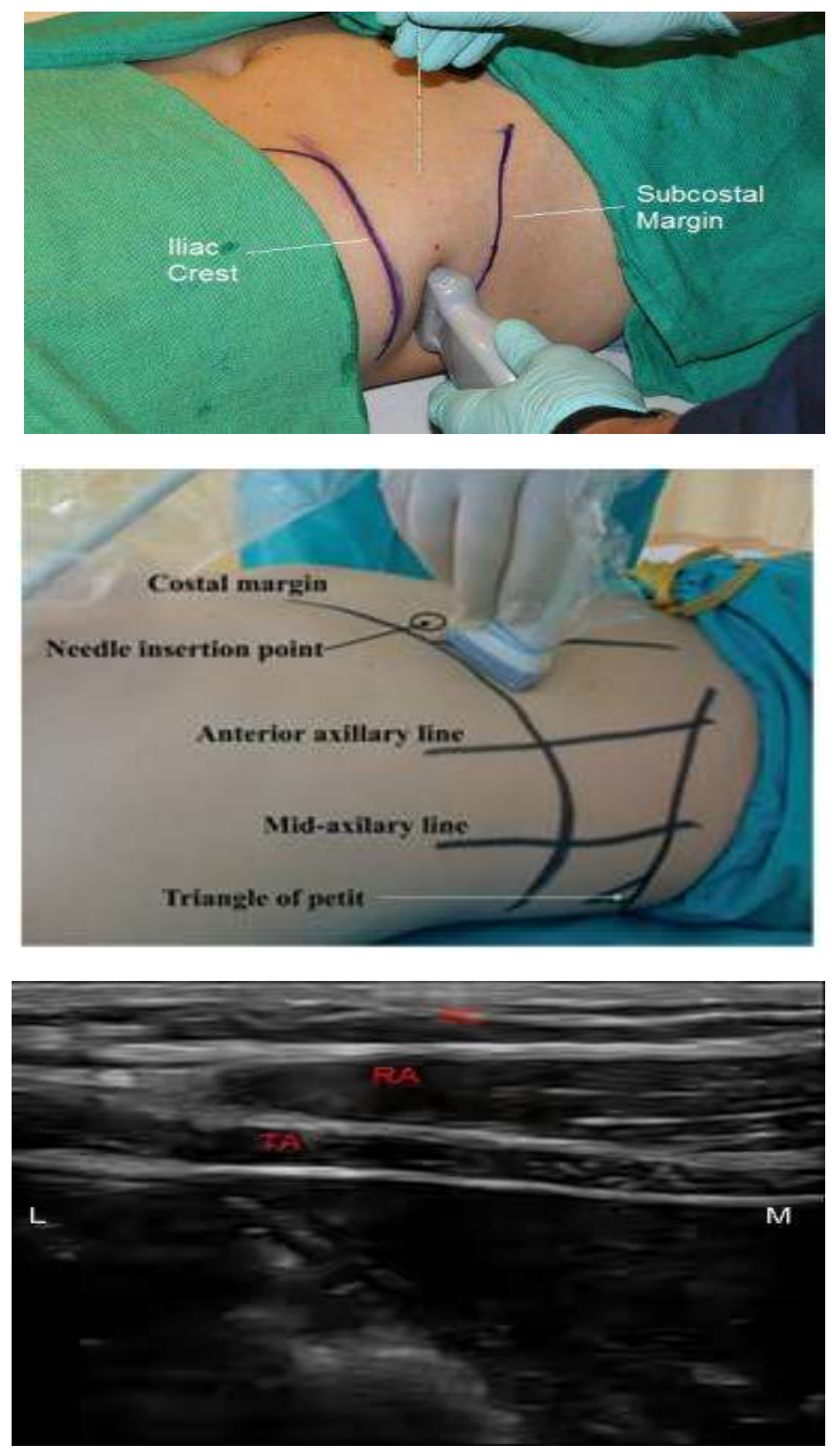

The Technique : A linear ultrasound probe (Micromaxx L38e/5-10 MHZ) was placed transversely on abdomen between costal margin and iliac crest in the mid-axillary line on the side to be blocked. The probe were slided anteriorly or posteriorly and tilted as necessary in a cephalo-caudal direction until a clear optimized image of the three lateral abdominal muscle (namely external oblique, internal oblique and transversusabdominis from outside inwards) and transversusAbdominis plane were visualized. Changing the depth and gain was to achieve further optimization of the image. An 18G Tuohy needle was introduced from an anterio-medial position to a posterior and lateral direction using in-plane technique with entry point in the skin being $2 \mathrm{~cm}$ away from the probe in order to improve needle visibility in the long axis. The needle trajectory proceeded in a anterio-posterior direction using in plane technique, with local anesthetic injection observed in real-time . 


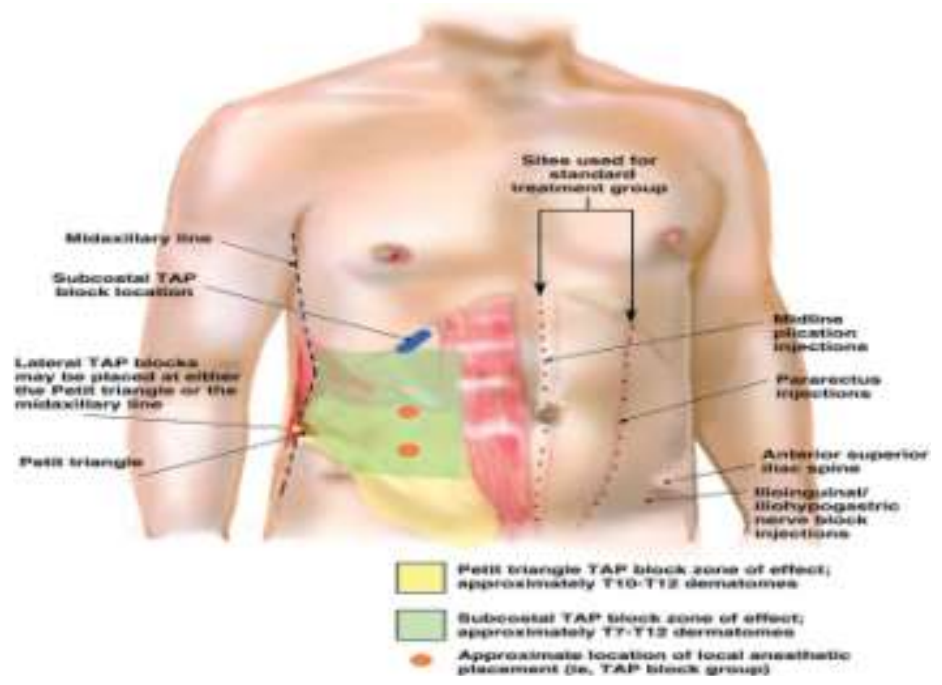

We used small dose first to confirm the transversusabdominis plane by observing the separation of fascia between internal oblique and transversusabdominis muscle. After confirming the transversusabdominis plane ,In Group-R patient use $20 \mathrm{ml} \mathrm{0.2 \%} \mathrm{Ropivacaine} \mathrm{plus} 1 \mathrm{ml}$ normal saline (Total $21 \mathrm{ml}$ ) was injected in Real time.

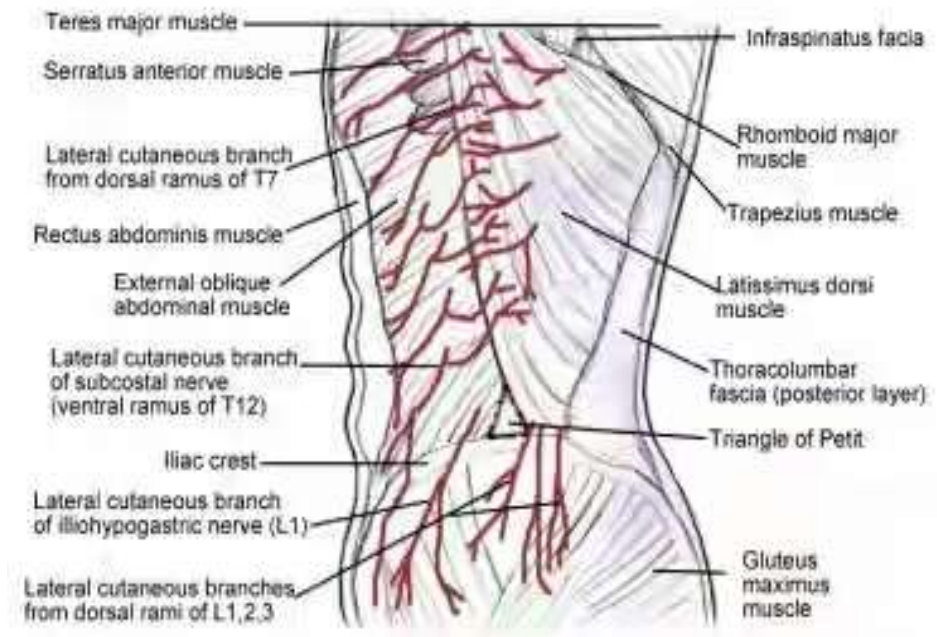

In Group-D patient, using same technique with $20 \mathrm{ml} 0.2 \%$ Ropivacaine with $0.5 \mathrm{mg} / \mathrm{kg}$ Dexmedetomedine (Total $21 \mathrm{ml}$ ) injected in plane.The above drugs will be used to compare the onset, quality and duration of postoperative analgesia in patients undergoing unilateral lower abdominal surgeries. Monitoring heart rate, ECG, blood pressure and $\mathrm{SpO}_{2}$ continuously and recording were made preoperatively and intraoperatively at 5 minutes interval.All the patient were observed in postoperative recovery room for post operative sedation (Ramsay sedation score from 1 to 6) all patient were assessed in post operative room for duration of analgesia upto 24 hour. The patient were assessed for pain based on VAS score. The patient were instructed how use a 10-mm visual Analogue scale for pain graded from 0 (no pain) to 10 (most severe pain)

Tramadol, $2 \mathrm{mg} / \mathrm{kg}$ i.v. was used as a rescue analgesic in patients who had VAS score >4 postoperatively.Comparability of groups was analyzed using student " $t$ " test. For all statistical analysis, the value of $\mathrm{P}<0.05$ was considered significant and value of $\mathrm{P}<0.001$ was considered highly significant.

The observations were tabulated as follows:

1- Demographic data of patients (age, sex, weight, height).

2- Pulse rate.

3-Mean blood pressure.

4-Duration of surgery.

5-Onset of Analgesia(minute)

6- Ramsay sedation score

7- Visual analogue score postoperatively. 
8-Time taken for first rescue analgesia.

9-Quality of analgesia.

10- Side effects or complications.

\section{Observation and Results}

\section{Results}

A total of 60 patients were selected in the study "comparison between $0.2 \%$ Ropivacaine versus $0.2 \%$ Ropivacaine with Dexmedetomidine in USG Guided TAP block for post operative analgesia in unilateral lower abdominal surgeries" comprising of 30 patients in each groups. Microsoft Excel 2010 and statistical software plug-ins used appropriate to test the significance of data. Data are being represented as mean \pm SD.A ' $p$ ' value of $<0.05$ was considered significant.

\begin{tabular}{|l|l|l|}
\hline $\begin{array}{l}\text { Table 1: Group } \\
\text { wise Distribution } \\
\text { of }\end{array}$ & Drugs used in USG guided TAP block & $\begin{array}{l}\text { Number } \\
\text { Patients }\end{array}$ \\
\hline PatientsGroups & & of \\
\hline Group R & Ropivacaine & 30 \\
\hline Group D & Ropivacaine+Dexmedetomidine & 30 \\
\hline
\end{tabular}

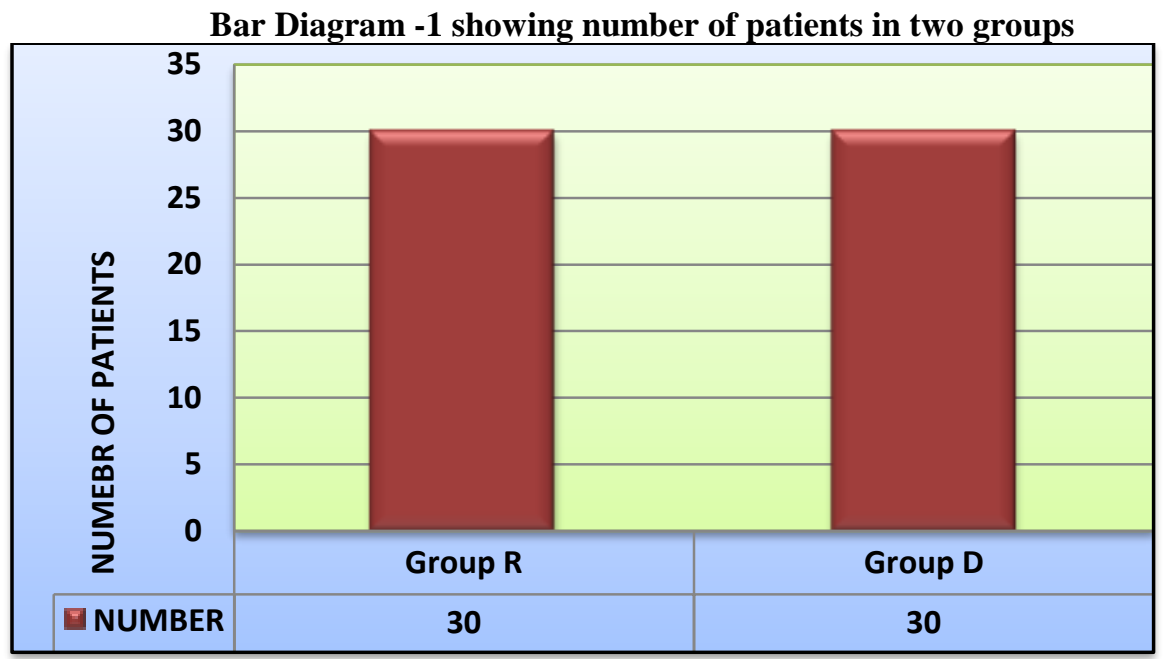

Table 2: Sex Distribution amongst the two groups

\begin{tabular}{|l|l|l|l|}
\hline Group R & Group D \\
\hline Male & 26 & Male & 27 \\
\hline Female & 4 & Female & 3 \\
\hline
\end{tabular}

Bar Diagram-2 showing sex distribution amongst the three groups

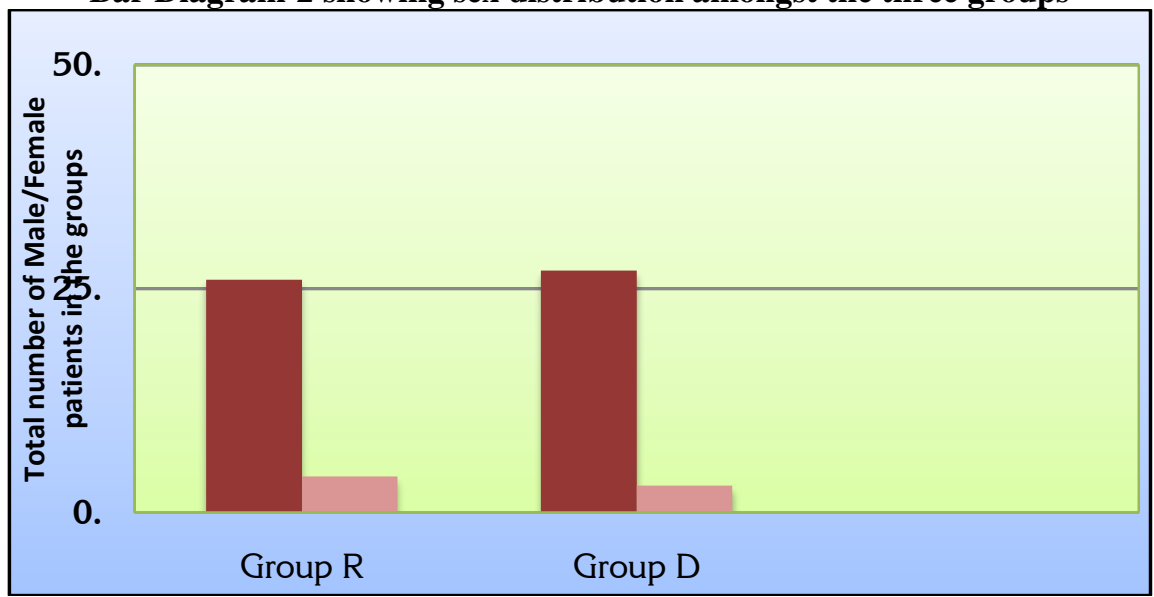


“Comparision Between 0.2\% Ropivacaine Versus 0.2\% Ropivacaine With Dexmeditomidine In...

Table 3: Comparison of Age,Weight and Height in two groups

\begin{tabular}{|l|l|l|l|}
\hline Demographic Profile & Group R & Group D & $\begin{array}{l}\text { p value } \\
\text { (ANOVA) }\end{array}$ \\
\hline Age(yrs) (Mean \pm SD) & $37.73 \pm 14.15$ & $42.06 \pm 24.48$ & 0.405 \\
Range (yrs) & $18-60$ & $24-60$ & \\
\hline Wt.(kg) (Mean \pm SD) & $61.7 \pm 8.48$ & $64.5 \pm 5.87$ & 0.142 \\
Range (kg) & $48-80$ & $50-74$ & \\
\hline Ht.(cm) (Mean \pm SD) & $161.71 \pm 6.55$ & $162.56 \pm 6.12$ & 0.627 \\
Range (cm) & $150-172$ & $150-175$ & \\
\hline
\end{tabular}

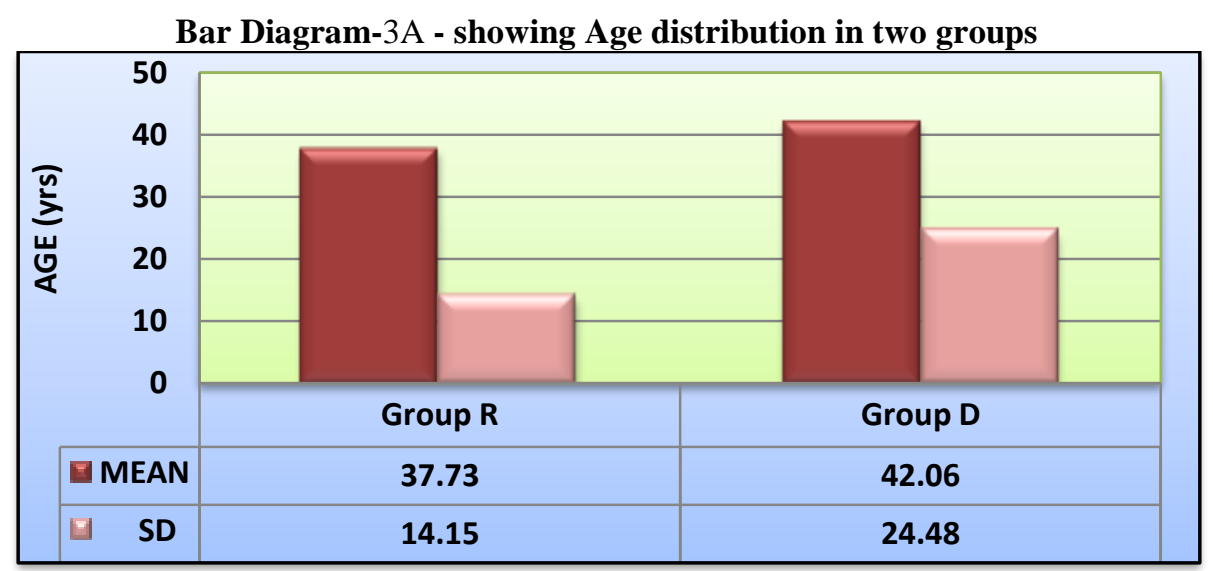

Inference: Statistically $(p>0.05)$ there was no difference in age of patients amongst the two groups.

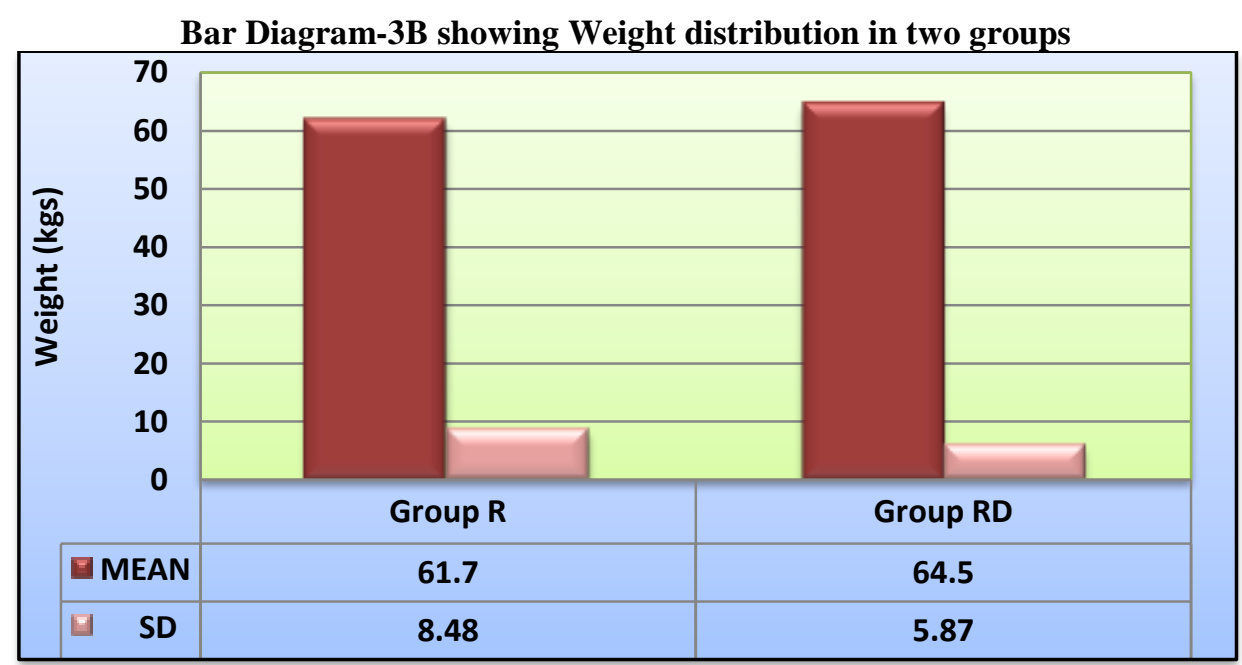

Inference: Statistically $(p>0.05)$ there was no difference in weight of patients amongst the two groups.

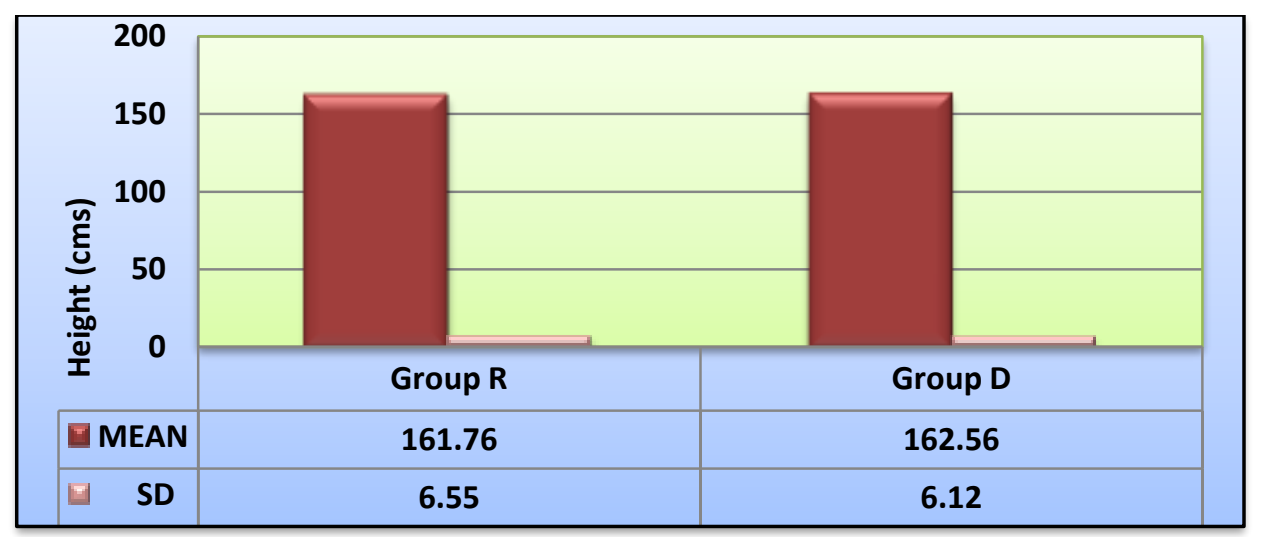

Bar Diagram-3C - showing Height distribution in two groups 
“Comparision Between 0.2\% Ropivacaine Versus 0.2\% Ropivacaine With Dexmeditomidine In...

Inference: Statistically ( $p>0.05)$ there was no difference in height of patients amongst the three groups.

Table 4: Distribution of patients according to duration of surgery in two Groups

\begin{tabular}{|l|l|l|}
\hline Group & $\begin{array}{l}\text { Duration of surgery (minutes) } \\
(\text { Mean } \pm \text { SD) }\end{array}$ & $\begin{array}{l}\text { P Value } \\
\text { (T test) }\end{array}$ \\
\hline Group R $(\mathrm{n}=30)$ & $89.5 \pm 15.5$ & 0.439 \\
\hline Group D $(\mathrm{n}=30)$ & $88.6 \pm 13.21$ & \\
\hline
\end{tabular}

As shown in Table 4, the mean duration of surgery between each group ( $p>0.05)$ was statistically insignificant.

Bar Diagram 4: Distribution of duration of surgery in two groups

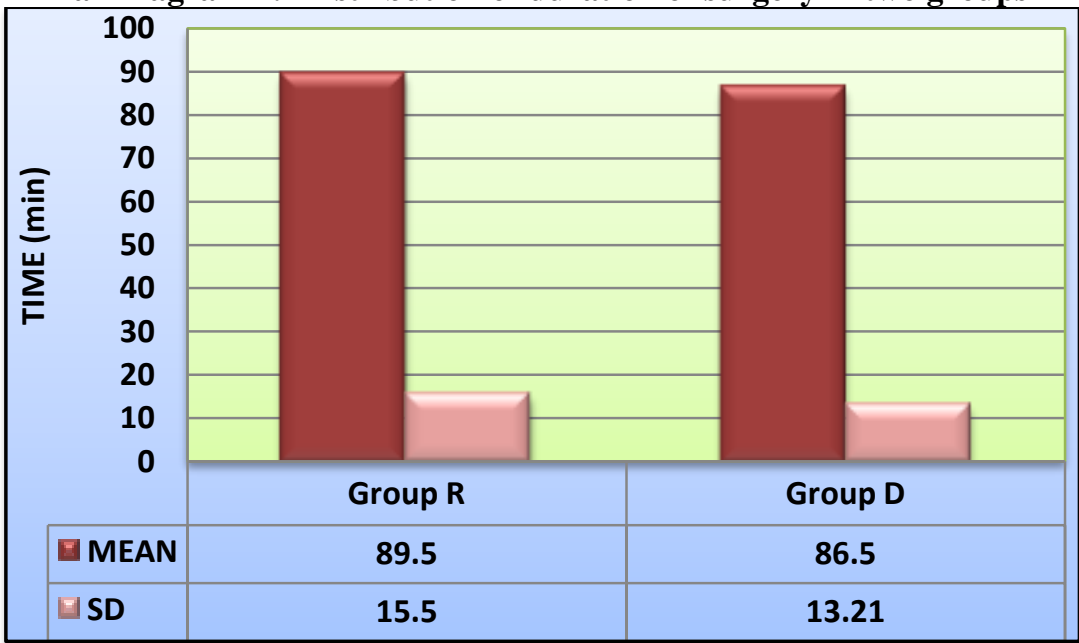

Inference: Statistically $(\mathrm{p}>0.05)$ there was no difference induration of surgery amongst the two groups.

Table 5: Mean Heart Rate (per minutes)

\begin{tabular}{|l|l|l|l|}
\hline $\begin{array}{l}\text { Heart rate } \\
\text { (per minute) }\end{array}$ & $\begin{array}{l}\text { Group R } \\
(\mathbf{n = 3 0})\end{array}$ & $\begin{array}{l}\text { Group D } \\
(\mathbf{n = 3 0})\end{array}$ & $\begin{array}{l}\text { P Value } \\
\text { (ANOVA) }\end{array}$ \\
\hline Baseline & $80.1 \pm 11.8$ & $85.2 \pm 14.6$ & 0.135 \\
\hline 0 minute & $87.60 \pm 7.54$ & $84.06 \pm 8.99$ & 0.104 \\
\hline 30 minute & $83.2 \pm 8.84$ & $80.5 \pm 10.57$ & 0.231 \\
\hline 60 minute & $83.4 \pm 8.74$ & $80.76 \pm 8.45$ & 0.239 \\
\hline 2 Hour & $82.9 \pm 8.98$ & $82.1 \pm 8.78$ & 0.728 \\
\hline 4 Hour & $83.7 \pm 8.88$ & $80.86 \pm 9.47$ & 0.236 \\
\hline 8 Hour & $87.8 \pm 9.53$ & $82.26 \pm 9.22$ & 0.540 \\
\hline 12 Hour & $85.6 \pm 10.2$ & $81.83 \pm 9.27$ & 0.140 \\
\hline 24 Hour & $89.6 \pm 10.53$ & $87.15 \pm 9.78$ & 0.350 \\
\hline
\end{tabular}

Table 5 shows the mean changes in heart rate of patients during intra operative period. The parameters had $\mathrm{P}>$ 0.05 which is statistically insignificant.

Bar Diagram 5 -Comparison of mean heart rate between two Groups

\begin{tabular}{|c|c|c|c|c|c|c|c|c|c|c|}
\hline \multirow{4}{*}{\multicolumn{2}{|c|}{ 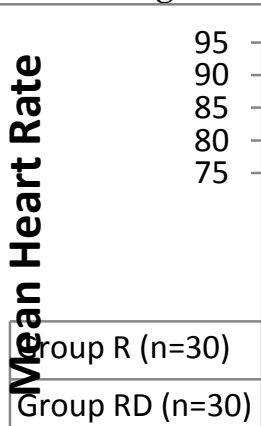 }} & 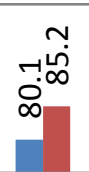 & $\begin{array}{l}60 \\
\text { i. } \\
\infty \\
\infty\end{array}$ & 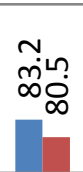 & $\begin{array}{l}+\infty \\
\text { mis } \\
\infty\end{array}$ & సָָָ & $\begin{array}{l}\text { ne } \\
\text { mீंீ } \\
\infty\end{array}$ & $\underset{\infty}{\infty} \underset{\infty}{\infty}$ & $\begin{array}{l}\varphi_{m} \\
\omega_{\infty}^{\infty} \infty \\
\dot{\infty}\end{array}$ & 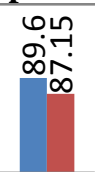 \\
\hline & & $\begin{array}{c}\text { Basel } \\
\text { ine }\end{array}$ & $\begin{array}{c}0 \\
\operatorname{minu} \\
\text { te }\end{array}$ & $\begin{array}{c}30 \\
\text { minu } \\
\text { te }\end{array}$ & $\begin{array}{c}60 \\
\text { minu } \\
\text { te }\end{array}$ & $\begin{array}{c}2 \\
\text { Hour }\end{array}$ & $\begin{array}{c}4 \\
\text { Hour }\end{array}$ & $\begin{array}{c}8 \\
\text { Hour }\end{array}$ & $\begin{array}{c}12 \\
\text { Hour }\end{array}$ & $\begin{array}{c}24 \\
\text { Hour }\end{array}$ \\
\hline & & 80.1 & 87.6 & 83.2 & 83.4 & 82.9 & 83.7 & 87.8 & 85.6 & 89.6 \\
\hline & & 85.2 & 84.06 & 80.5 & 80.76 & 82.1 & 80.86 & 82.26 & 81.83 & 87.15 \\
\hline
\end{tabular}

*Inference: Statistically ( $>>0.05)$ there was no difference inmean heart rate of patients amongst the two groups. 
“Comparision Between 0.2\% Ropivacaine Versus 0.2\% Ropivacaine With Dexmeditomidine In...

* There is no statistically significant difference in Heart rate after giving TAP block upto 12 hrs in Group R.

* There is increased heart rate after 12 hrs of TAP block but not significant.

* There is no statistically significant difference in Heart rate after giving TAP block upto 24 hrs in Group D.

Table 6: Mean Arterial Pressure ( $\mathrm{mm} \mathrm{Hg}$ )

$\{$ MAP $=$ DBP $+1 / 3($ SBP - DBP $)\}$

\begin{tabular}{|c|c|c|c|c|}
\hline $\begin{array}{l}\text { Arterial } \\
(\mathrm{mm} \mathrm{Hg})\end{array}$ & Pressure & $\begin{array}{l}\text { Group R } \\
(\mathbf{n}=\mathbf{3 0})\end{array}$ & $\begin{array}{l}\text { Group D } \\
(\mathbf{n}=\mathbf{3 0})\end{array}$ & $\begin{array}{l}\text { P Value } \\
\text { (ANOVA) }\end{array}$ \\
\hline Baseline & & $87.5 \pm 2.78$ & $88.7 \pm 3.03$ & 0.115 \\
\hline 0 minute & & $92.83 \pm 7.32$ & $94.06 \pm 6.18$ & 0.485 \\
\hline 30 minute & & $84.26 \pm 9.53$ & $86.5 \pm 6.60$ & 0.294 \\
\hline 60 minute & & $81.4 \pm 8.64$ & $81.2 \pm 3.03$ & 0.905 \\
\hline 2 Hours & & $83.3 \pm 8.43$ & $82.3 \pm 3.99$ & 0.559 \\
\hline 4 Hours & & $80.4 \pm 9.33$ & $80.43 \pm 7.78$ & 0.370 \\
\hline 8 Hours & & $87.9 \pm 9.08$ & $85.03 \pm 7.25$ & 0.181 \\
\hline 12 Hours & & $88.5 \pm 8.24$ & $80.4 \pm 8.37$ & 0.332 \\
\hline 24 Hours & & $86.6 \pm 6.79$ & $89.6 \pm 6.87$ & 0.118 \\
\hline
\end{tabular}

* MAP - Mean Arterial Pressure

* SBP - Systolic Blood Pressure

* DBP - Diastolic Blood Pressure

Table 6 shows the changes in mean arterial pressure of patients during intra operative period. The parameters had $\mathrm{p}>0.05$ which is statistically insignificant.

Bar Diagram 6 -Comparison of mean arterial pressurebetween two Group

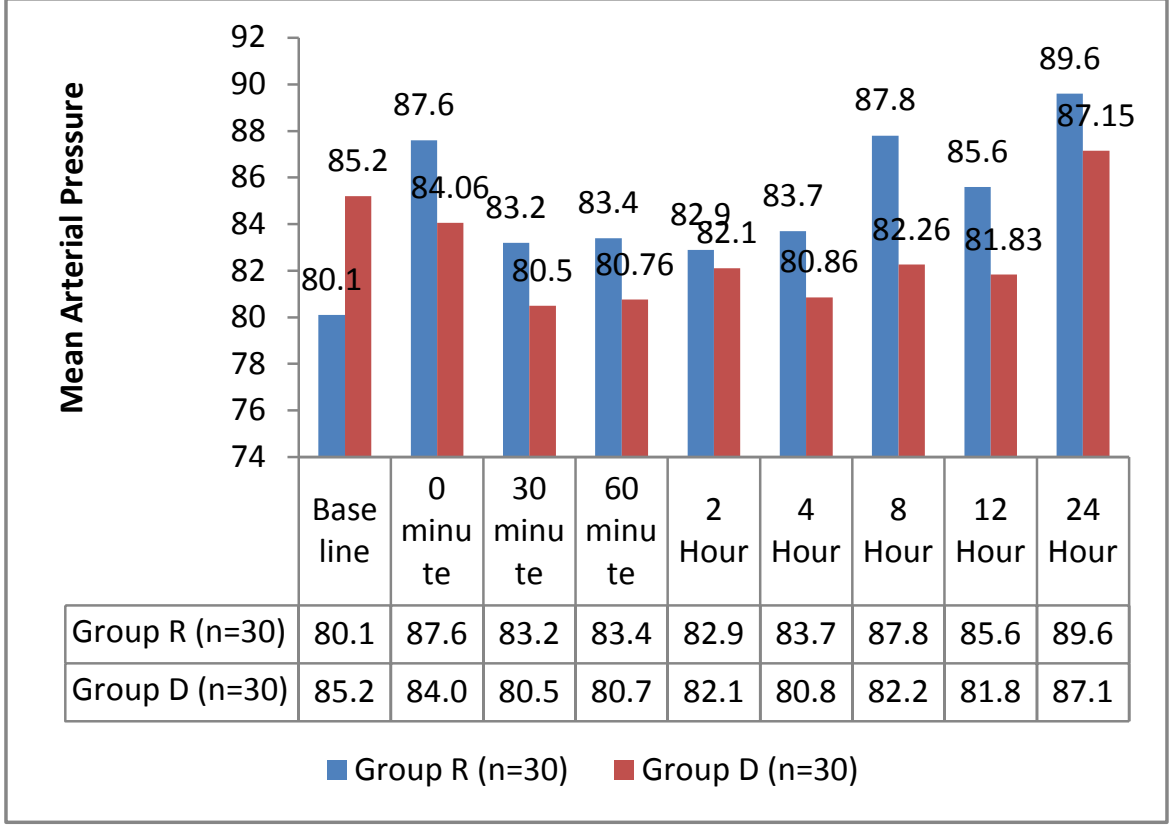

*Inference: Statistically ( $p>0.05)$ there was no difference in mean arterial pressure of patients amongst the two groups

Table 7: Comparison of Onset of Analgesia in two groups

\begin{tabular}{|l|l|l|l|}
\hline $\mathbf{N = 3 0}$ & Group R & Group D & P Value (ANOVA) \\
\hline Mean \pm SD (min) & $11.03 \pm 2.45$ & $8.67 \pm 1.51$ & $<0.0001$ \\
\hline Range (min) & $8-15$ & $7-12$ & \\
\hline
\end{tabular}


“Comparision Between 0.2\% Ropivacaine Versus 0.2\% Ropivacaine With Dexmeditomidine In...

Bar Diagram-7 Comparison of Onset of Analgesia in two groups

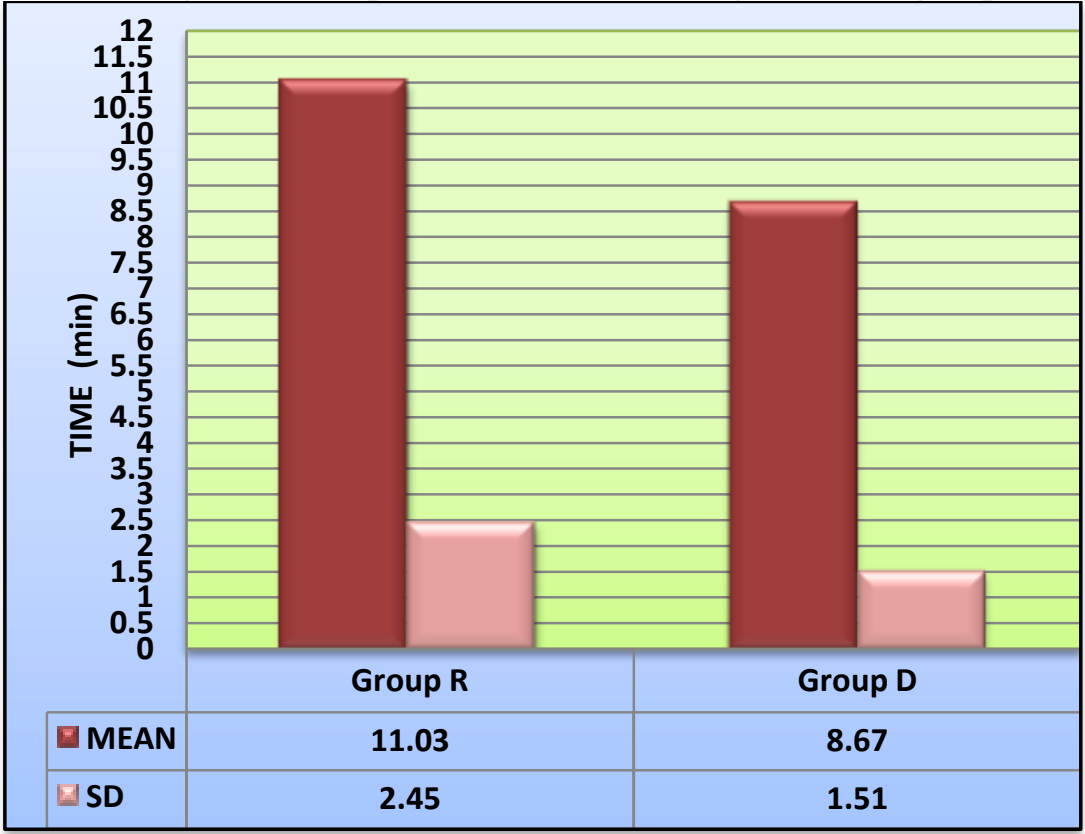

*Inference: Statistically $(\mathrm{p}<0.001)$ there was difference in onset of analgesia of patients amongst the two groups

In Group R onset time of analgesia is more than D is statically more significant.

Table 8: Comparison of duration of Analgesia in two groups

\begin{tabular}{|l|l|l|l|}
\hline $\mathrm{N}=20$ & Group R & Group D & P Value (ANOVA) \\
\hline Mean \pm SD (Hours) & $20.8 \pm 4.62$ & $24.03 \pm 5.02$ & $<0.001$ \\
\hline $\begin{array}{l}\text { Range } \\
\text { (Hours) }\end{array}$ & $12-26$ & $12-32$ & \\
\hline
\end{tabular}

Bar Diagram 8: Distribution of duration of Analgesia in two group

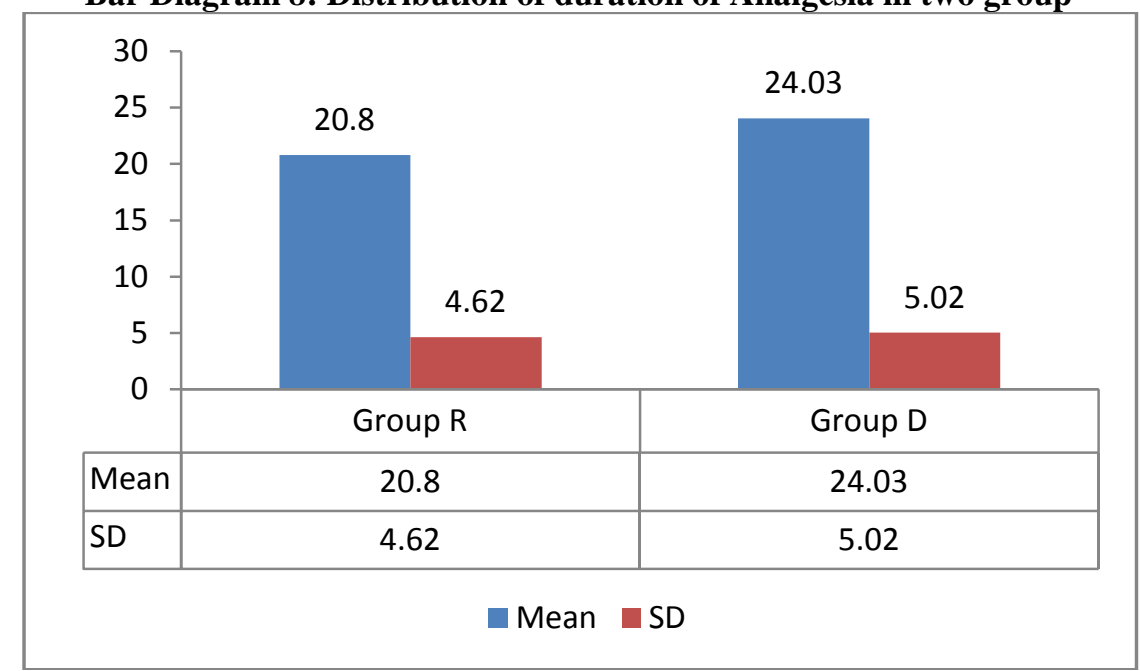

Inference: Statistically $(\mathrm{p}<0.001)$ there was HIGHLY SIGNIFICANT difference inDuration of analgesia (min) amongst the two groups.

Table 9: Comparison of VAS Score in two groups

\begin{tabular}{|l|l|l|l|}
\hline $\mathbf{N}=\mathbf{3 0}$ Mean \pm SD & Group R & Group D & P value \\
\hline 8 Hours & $1.2 \pm 0.80$ & $0.90 \pm 0.607$ & 0.106 \\
\hline 12 Hours & $1.90 \pm 0.12$ & $1.43 \pm 0.89$ & 0.07 \\
\hline 24 Hours & $3.06 \pm 1.31$ & $2.30 \pm 1.235$ & 0.02 \\
\hline
\end{tabular}

Diagram-9A showing VAS Scoring in the two groups at 8 hours 
“Comparision Between 0.2\% Ropivacaine Versus 0.2\% Ropivacaine With Dexmeditomidine In...

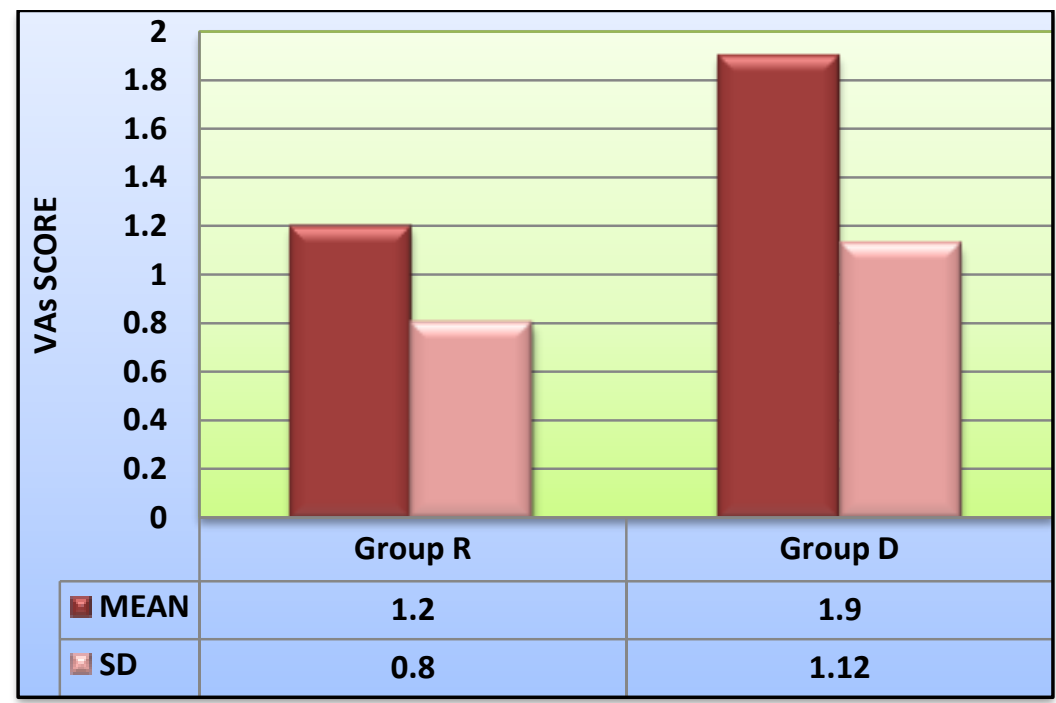

Inference: Statistically ( $p>0.05)$ there was no SIGNIFICANT difference in VAS score amongst the two groups at 8 hours.

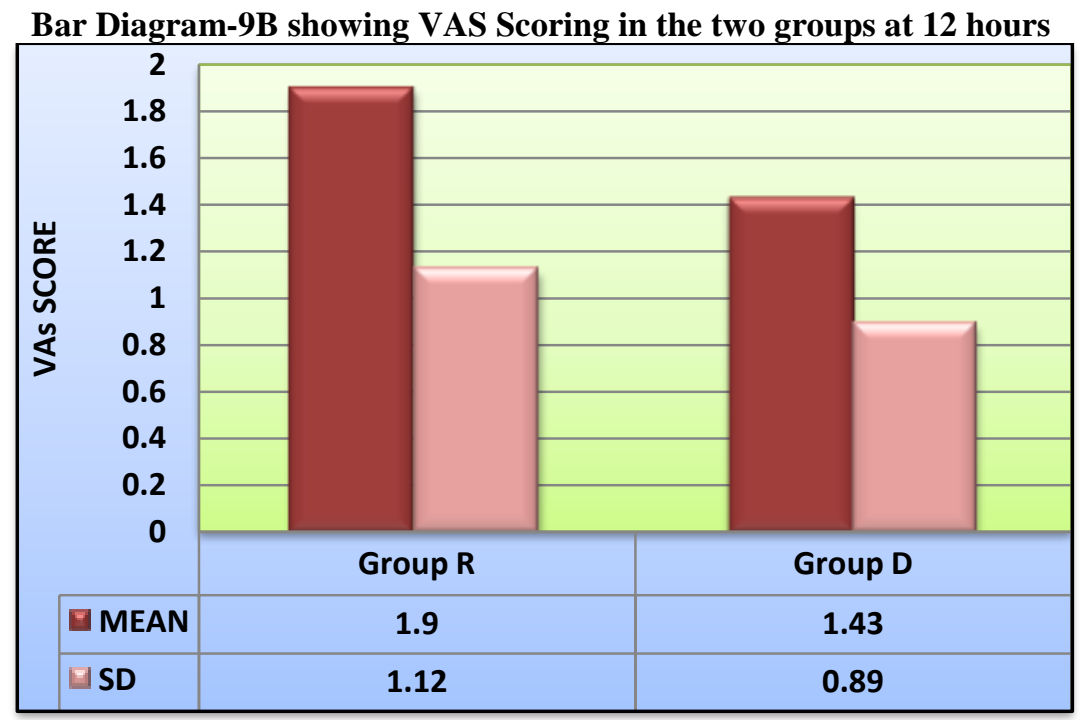

Inference: Statistically ( $>0.05)$ there was no SIGNIFICANT difference in VAS score amongst the two groups at 12 hours.

Bar Diagram-9C showing VAS Scoring in the two groups at 24 Hours

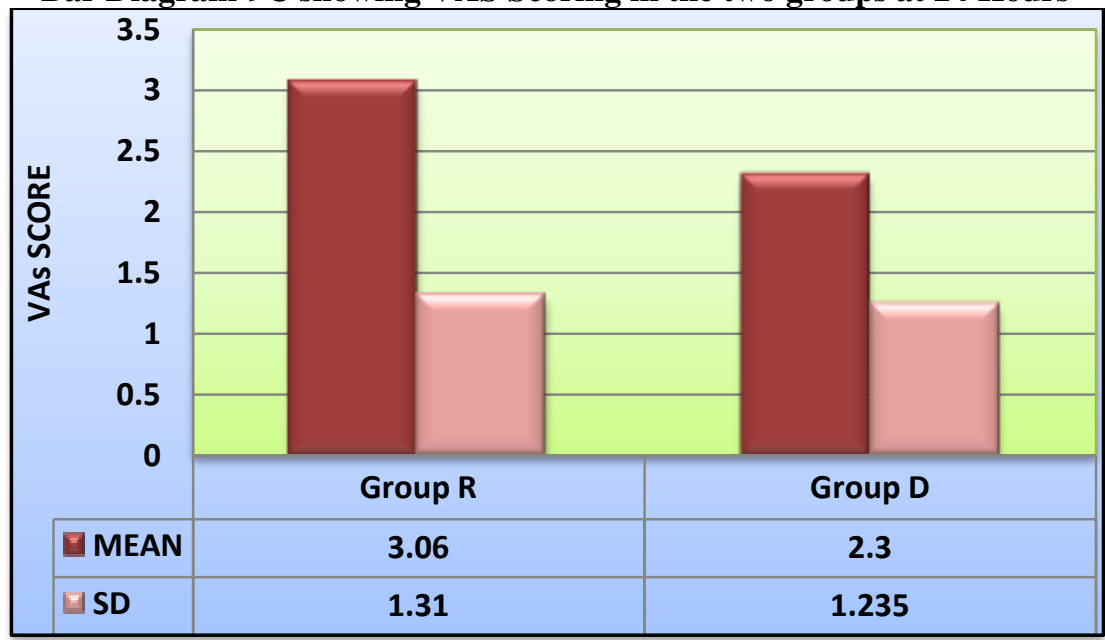

Inference: Statistically $(\mathrm{p}<0.05)$ there was SIGNIFICANT difference in VAS score amongst the two groups at 
24 hours

Table 10: Comparison of Ramsay Sedation Score

\begin{tabular}{|l|l|l|l|}
\hline Sedation Score & $\begin{array}{l}\text { Group R } \\
(\mathbf{n = 3 0})\end{array}$ & $\begin{array}{l}\text { Group D } \\
(\mathbf{n = 3 0})\end{array}$ & $\begin{array}{l}\text { P Value } \\
\text { (ANOVA) }\end{array}$ \\
\hline 0 minute & $1.16 \pm 0.37$ & $1.96 \pm 0.61$ & 0.00 \\
\hline 30 minute & $1.13 \pm 0.34$ & $1.93 \pm 0.44$ & 0.00 \\
\hline 60 minute & $1.03 \pm 0.18$ & $1.5 \pm 0.57$ & 0.00 \\
\hline 2 Hours & $0.96 \pm 0.18$ & $1.13 \pm 0.52$ & 0.125 \\
\hline 4 Hours & $0.93 \pm 0.253$ & $0.83 \pm 0.53$ & 0.354 \\
\hline 8 Hours & $0.90 \pm 0.30$ & $0.56 \pm 0.50$ & 0.708 \\
\hline 12 Hours & $0.73 \pm 0.44$ & $0.57 \pm 0.46$ & 0.174 \\
\hline 24 Hours & $0.57 \pm 0.46$ & $0.67 \pm 0.40$ & 0.373 \\
\hline
\end{tabular}

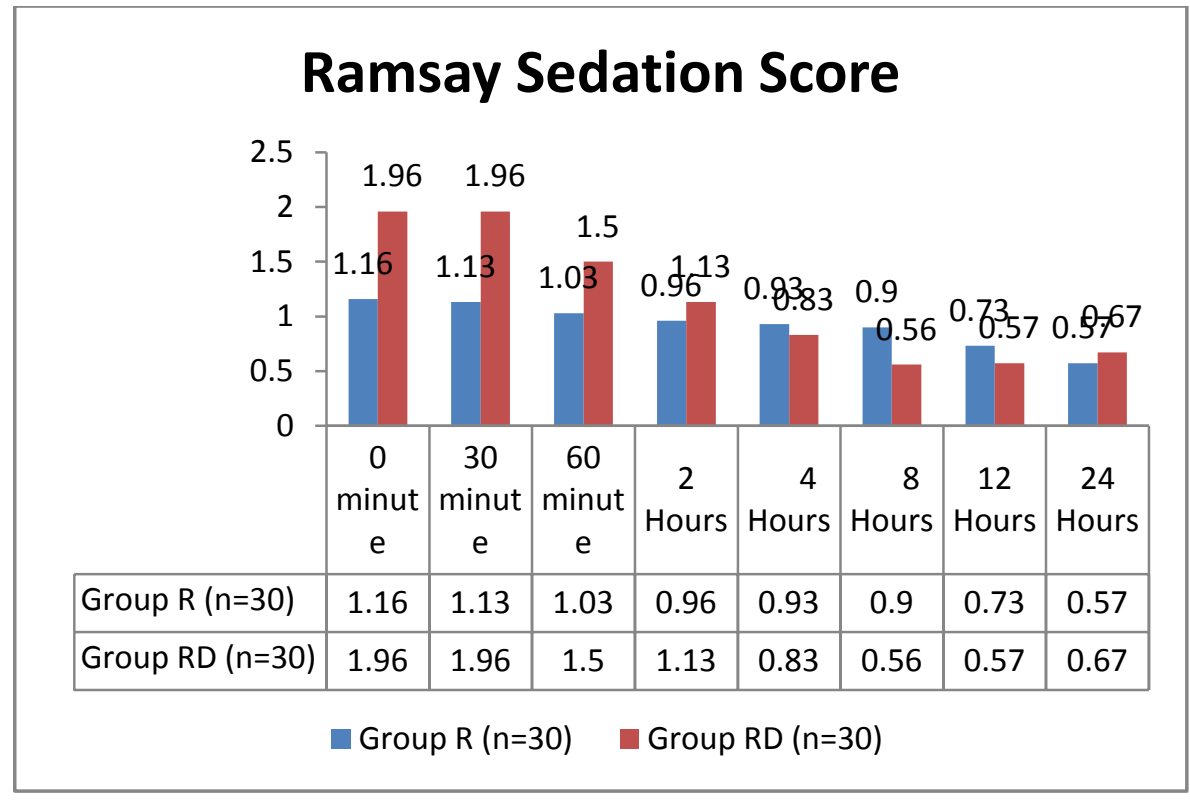

Table 11: Comparison of Total no. of Rescue Analgesics in 24 hrs in two groups

\begin{tabular}{|l|l|l|l|}
\hline $\mathbf{N}=\mathbf{3 0}$ & Group R & Group D & P Value (ANOVA) \\
\hline Mean \pm SD & $3.13 \pm 0.86$ & $1.9 \pm 1.14$ & $<0.001$ \\
\hline
\end{tabular}

There is more statically significant of duration of analgesia of two Group $(p<0.05)$.

Number of rescue analgesia more in R Group than D.

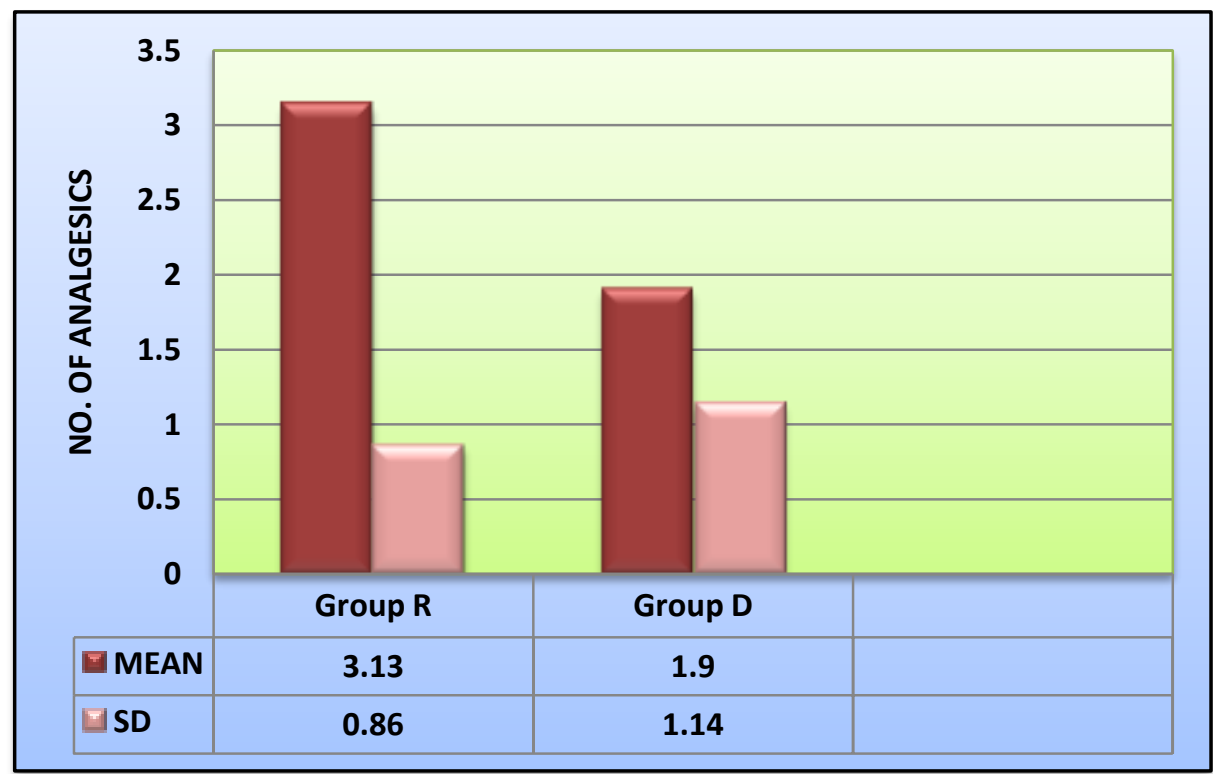




\section{Discussion}

Transversusabdominis plane (TAP) block is a new rapidly expanding regional anaesthetic technique that provide analgesia following abdominal surgery. TAP block significantly reduce pain associated with lower abdominal surgery, regardless of whether it is used as primary anaesthetic or for pain postoperatively.The TAP is used to approach and block the abdominal wall neural afferents. The sensory supply of the skin, muscles and parietal peritoneum of the anterior abdominal wall is derived from the anterior rami of the lower six thoracic nerves and the first lumber nerve. The intercostals, subcostal, iliohypogastric and ilionguinal nerves course through the lateral abdominal wall within the TAP before they pierce the musculature to innervate the abdomen. There is extensive branching and between nerves within the TAP ${ }^{(\mathbf{8})}$.

The use of ultrasound was introduced to improve the success rate and accuracy of TAP block and to prevent potential complications. The block is technically easier to perform in elderly patients on account of loss of muscle mass and tone. It may not be easy in obese patients, in whom the neddle insertion point can be $2.5 \mathrm{~cm}$. behind the highest point of the iliac-crest, the distance from the skin to TAP can be long, and two 'pop' sensations may not be obious.

In our study we compared the above two Drugs for efficacy, safety and postoperative analgesia in unilateral lower abdominal surgery in above 18-60 years of age of both sex.

The present study "comparision between $0.2 \%$ Ropivacaine versus 0.2\%Ropivacaine with Dexmeditomidine in ultrasound guided TransversusAbdominis Plane block for post operative Analgesia in unilateral Lower abdominal surgeries" was conducted in the department of anaesthesiologySwaroop Rani Nehru Hospital, MLN medical college, Allahabad, U.P., India.

Our study had 60 patients of more than 18 years of age, posted for lower abdominal surgery that were randomly allocated into two groups.

Group-R: Consisted of 30 patients who received USG Guided TAP block with $20 \mathrm{ml}$ of $0.2 \%$ Ropivacaine.

Group-D: Consisted of 30 patients who received USG Guided TAP block with $20 \mathrm{ml}$ of $0.2 \%$ Ropivacaine with $0.5 \mu \mathrm{gm} / \mathrm{kg}$ Dexmeditomidine.

Ropivacaine is long acting local anesthetic drug that is structurally related to bupivacaine, unlike bupivacaine which is racemate, Ropivacaine is a pure s (-)enantiomer developed for the purpose of reducing the potential toxicity and improving the relative sensory and motor block profiles.

Analgesia efficacy of Ropivacaine is similar or slightly less than bupivacaine. Intrathecaly administered Ropivacaine as a part of combined spinal epidural technique produces rapid and effective in lobour pain relief with less incidence of motor block.

Shibata et al (2007) ${ }^{(17)}$ have performed transversusabdominis plane block under ultrasound guidance in patients undergoing gynecological surgeries. They assessed the extent of ultrasound guided TAP block by pinprick in 26 patients undergoing laparoscopic gynecological surgeries. The mean upper and lower level of sensory block at $30 \mathrm{~min}$ after local anesthetic injection were T10 (range, T9-11) and L1 (range, T12-L1), respectively, providing good post operative analgesia in patient of full length of midline incisions.

Our study dissimilar with above mention study. we observe the onset, quality and Duration of two drugs in group Rand D. each group has 30 patient block was given after finessed of unilateral lower abdominal surgery after general anesthesia. Time of Onset of analgesia in group $\mathrm{D}(8.67 \pm 1.51)$ is less than group $\mathrm{R}(11.03 \pm 2.45)$ where $\mathrm{p}<0.0001$ is more significant .

K. O Connor et al (2010) ${ }^{(71)}$ reported that their 4 point TAP block was effective in managing pain, decreasing opiods consumption, safe alternative to neuroxial blockage in patient who are cogulopathic or patient who do not tolerate the haemodynamic after associated with sequelae of neuraxialsymapathectom.

In group-R of our study blood pressures increased but was non- significant. This rise in blood pressure could be attributed to anxiety, non usage of sedatives or inability to attained excellent quality of block. As the visceral pain is not relieved in TAP block, the quality of block is good to moderate and never excellent in surgeries involving visceral structures as in our case with inguinal hernia surgeries.

Nesek Adam et al (2011) ${ }^{(45)}$ conducted a prospective, randomized study to compare between unilateral and bilateral spinal anesthesia in hypertensive patients undergoing surgery for varicose veins, and found the mean time for peak onset of sensory block was $5.4 \pm 0.8 \mathrm{~min}$ in their unilateral group as compared to $5.1 \pm 0.8 \mathrm{~min}$ in bilateral group.

In group-R are of our study time to reach the highest time of onset of Analgesia was $11.03 \pm 2.45$ min. compare to Group -D was $8.67 \pm 1.51$ Thus the results of our study was comparable to the above studies.In the study of Nesek Adam et al (2011), for comparison between unilateral and bilateral spinal anaesthesia, mean modified bromage scale was $2.5 \pm 0.6 \mathrm{~min}$ in unilateral and $2.4 \pm 0.6 \mathrm{~min}$ in bilateral group at 15 minute of block. 
Thus result of our study different.

On statistical evaluation this difference was statistically significant ( $\mathrm{p}$ value $>0.5$ ) at $0 \mathrm{~min}$, 30min, $1 \mathrm{hrs}$., $2 \mathrm{hrs}$., $4 \mathrm{hrs}$, $8 \mathrm{hrs}$, $12 \mathrm{hrs}$ after This rise in pulse rate may be attributed to many factors like anxiety, non usage of sedative or inability to achieve excellent grade of block with TAP block.In group-D pulse rate was lower compared to their pre-procedure value at all time interval measured. Pulse rate was gradually returned to pre-procedure values after 20 minutes. One patient (5\%) showed bradycardia (HR $<55 / \mathrm{min}$ ) that was treated with $0.3 \mathrm{mg}$ of atropine IV bolus.

On statistical evaluation this difference was statistically No significant ( $\mathrm{p}$ value $>0.05$ ) at 0 and at 30 minute Pulse rate compared between two groups (intergroup) showed that there was no significant difference in pulse rate $(\mathrm{p}>0.05)$ between two groups before procedure.In group-R Mean blood pressure were slightly higher as compared to group- $\mathrm{D}$ value but this difference was statistically not significant $(\mathrm{p}>0.05)$ at any time interval. comparison of mean blood pressure measured at 0mint, 30mint, $1 \mathrm{hrs,}$ $2 \mathrm{hrs}, 4 \mathrm{hrs}, 8 \mathrm{hrs}, 12 \mathrm{hrs}, 24 \mathrm{hrs}$ after surgery which were compared to their pre-procedure values.

Table- 6 in group- $\mathrm{R}$ the mean blood pressure was slightly higher as compared to their preprocedure value but not statistically significant at any time intervals. In group-D mean blood pressure decreased slightly compared to their pre-procedure value but statistically not significant at any time interval.Thus the results of our study was comparable to the above studies. time taken for first rescue analgesia is more in group- $\mathrm{R}(3.13 \pm 0.86)$ and $\mathrm{D}(1.90 \pm 1.14)$. On statistical evaluation this difference was highly significant ( $\mathrm{p}$ value <0.001).shows mean VAS score in first 24 hours in both groups immediately after surgery and at $0,30 \mathrm{mint}, 1 \mathrm{hrs}, 2 \mathrm{hrs}, 4,8,12$, and 24 hours postoperatively. after $8 \mathrm{hrs}$ of surgery mean VAS score was more in group-R and maximum at 24 hours $(3.06 \pm 1.31)$ in comparison to group-D $(2.30 \pm 1.23)$ that was statistically significant $(\mathrm{p}<0.02)$. Iyad Abbas Salman et al $(\mathbf{2 0 1 2})^{(27)}$ have observed in their comparison between TAP block and parenteral analgesia post caesarean section that traditional treatment had in $1^{\text {st }} 2$ hours whereas TAP block was better thereafter.Our study different of this study. We compare the onset, quality and duration of analgesia of two drugs of different group of same concentration.

FarheenMirza et al (2013) ${ }^{(28)}$ presented a case series on "Transversusabdominis plane blocks for rescue analgesia following Caesarian delivery" and they observed that in 1st case after 20 minutes of TAP block, VAS score decreased from 9 to 2 and the patient's next request for further analgesia was 12.3 hours after the block. In the 2nd case after 18 minutes of TAP block, VAS score decreased from 10 to 3 and the pt's next request for further analgesia was 10.3 hours. In the 3rd case, after 27 minutes of TAP block VAS score decreased from 9 to 2 and the duration of analgesia was 19.9 hour.

Our study nearly same of this study after TAP block compare the hemodynamic condition of group R and Group D .both groups patient has hemodynamically stable slightly increase in MAP and pulse rate in group $\mathrm{R}$ after 12 houre compare of group $\mathrm{D}$.No nausea and vomiting has been reported .

SulagnaBhattacharjee et al (2014) ${ }^{\mathbf{( 3 0 )}}$ use term Analgesic efficacy of TransversusAbdominis plane block in providing effective perioperative analgesia in patiens undergoing total abdominal hysterectomy . a total 90 adult female patients ASA-1 and llnd were randomized to group $\mathrm{B}(\mathrm{n}=45)$ receiving TAP block with $0.25 \%$ bupivacaine and Group-N $(\mathrm{n}=45)$ with normal saline followed by General Anesthesia. the hemodynamic responses surgical incision and consumption of intraoperative Fentanyl were noted.VAS were assessed at $1,2,3,4,5,6$, and 24 hours .fist rescue analgesia (when VAS $>4 \mathrm{~cm}$ or on demand). Mean blood pressure was also compared between two groups (intergroup). Mean blood pressure were comparable in both groups significantly higher in Group-N. VAS at rest $(3 \mathrm{~mm}$ vs $27 \mathrm{~mm}$ ) with activity $(8 \mathrm{~mm}$ vs $35 \mathrm{~mm}$ ) in group-B significantly lower compared to group $\mathrm{N}$

In our study age ,sex,type of surgery and duration of surgery does not effect onset ,quality and duration of analgesia after TAP block. In Table-7compare onset of analgesia group $-\mathrm{R}(11.03 \pm 2.45)$ and Group$\mathrm{D}(8.67 \pm 1.51)$ Statistically $\mathrm{p}<0.001$ more significant.Table $-9 \mathrm{~b}$ and $9 \mathrm{c}$ show VAS at $12 \mathrm{hr}$ and $24 \mathrm{hrs}$ at $24 \mathrm{hr}$ VAS more in group R Than D.

Gildasio S. de Oliveira Jr. et al (2014) ${ }^{(72)}$ analyzed ten randomized clinical trials to evaluate the effects of TAP block compared with an inactive group (placebo or "no treatment") on postoperative pain outcomes in laparoscopic surgery. They analyzed postoperative pain at rest and on movement and postoperative opioid consumption (up to 24 hours). These ten clinical trials included 633 patients ( 346 patients receiving TAP block and 287 patients on control group) who suffered laparoscopic surgeries (gastric bypass, bariatric surgery, colorectal surgery, cholecystectomy, hysterectomy and nephrectomy). The first thing analyzed was early (0-4 hours) pain at rest in 6 studies and early pain on movement in 4 studies. For the first (rest group) subgroup analysis revealed a greater effect on early pain at rest when TAP block was performed preoperatively, compared with postoperatively. The others 4 studies evaluating the effect of TAP block on early pain on movement compared with control did not show a significant benefit. For the late pain (24 hours) at movement, this studydid not find a significant effect of TAP block compared with control groups. Postoperative opioid 
consumption (up to 24 hours) was also significantly reduced. After their meta-analysis, TAP block has a significant effect in reduction postoperative pain (early and late pain at rest) and opioid consumption for laparoscopic surgical procedures, which suggests that this technique may be an effective strategy to improve analgesic outcomes. Another important finding of their investigations was that administration of TAP block preoperatively has more benefits than the postoperative one. They also detected a relationship between the local anesthetic dose and the effect on some outcomes - higher doses of local anesthetic did not lower early postoperative pain but it has greater opioid-sparing effects and lower pain scores at 24 hours.

Our study nearly same with some differences as we use TAP block after completion of surgery because may be Interfere result of study .Our study has better outcome in group D due to use of Dexmedetomidine with Ropivacaine than group- $\mathrm{R}$ ( Ropvacaine ).in Table -11 Requirement rescue analgesia in group $\mathrm{R}(3.13 \pm 0.86)$ is more than group $\mathrm{D}(1.9 \pm 1.14) \mathrm{P}<0.05$ is statistically more significant Venkatraman et al(jan 2016) (73) undergoing 60 patient inguinal hernioplasty of ASA-1 and ASA-2 of 18 to 60 years age group.at the end of surgery ,they were randomaly divided into two group .USG guided TAP block was performed with $20 \mathrm{ml} \quad 0.2 \%$ ropivacaine(group A)or normal saline (group B) VAS is assessed patient given iv paracetamol if VAS $>3$ and use tramadol vas $>6$ in dose $1.5 \mathrm{mg} / \mathrm{kg}$.

There was no statically significant difference in VAS score at 0,2 , and 24 hours. But VAS score were significantly less in group B at 4, 6, and 12 hours and given in Table 3 . The time at which paracetamol was required was substantially longer in group A (439.50 minutes) than group B (233.50 minutes). The total paracetamol requirement in the first 24 hours were considerably less in group $\mathrm{A}(1.27 \pm 0.64$ doses) than group $\mathrm{B}$ $(2.53 \pm 0.68$ doses $)$. Similarly the tramadol requirement was more in group B $(1.47 \pm 0.78$ doses $)$ than group A $(0.6 \pm 0.49$ doses.

There were no significant variations in heart rate, blood pressure, and oxygen saturation in both the groups. No complication was reported in both the groups.

Our study has inaccordance of this study in Table 3 and Table4 does not effect onset, duration and quilty of TAP block. Table 7 0nset of analgesia early in group D where $p<0.001$ is statistically more significant . Table 8 Duration of analgesia in Group R(20.8 \pm 4.62$)$ than group D $(24.03 \pm 5.02)$ where $p<0.001$ is statistically more significant. In Table -9 a,b,c showing VAS Scoring at 8,12and 24 hours in group R and group D at 24 hour VAS more in group $\mathrm{R}(3.06 \pm 1.31)$ than group $\mathrm{D}(2.30 \pm 1.235)$ Where $\mathrm{P}<0.02$ statistically more significant.show that requirement of resique analgesia is more in group $\mathrm{R}$.

Dr.PrashantRai, Dr.Devendra Singh Negi,Dr.S.KSingh,Dr.DeepakMalviya (Feb2016) ${ }^{(74)}$ Atotal of 100 patients scheduled to undergo caesarean section were divided into two groups in a randomized double blinded way. InGroup R ( $\mathrm{n}=50)$ patients will receive TAP block on each side using $22 \mathrm{ml}$ of study medication, which will consist of $20 \mathrm{ml}$ of ropivacaine $0.25 \%$ and $2 \mathrm{ml}$ of normal saline. While Group RD $(\mathrm{n}=50)$ patients will receive TAP block on each side with $22 \mathrm{ml}$, in which dexmedetomidine $0.5 \mathrm{mcg} / \mathrm{kg}$ will be dissolved in 2 $\mathrm{ml}$ of normal saline and added to $20 \mathrm{ml}$ of ropivacaine $0.25 \%$. Time to administration of first dose of analgesic,total dose of rescue analgesia, pain scores, hemodynamic data and side-effects were recorded.

The time for first analgesic dose was longer in Group RD than Group R [280 vs. 190 min, $\mathrm{P}<0.001]$ and the total dose ofTramadol used in the first 24 hours was less among patients in Group RD when compared with those in Group R [71 vs. $98 \mathrm{mg}, \mathrm{P}<0.001$ ]. VAS was significantly reduced at all post-operative points for the first $6 \mathrm{~h}$ in Group RD compared with Group R, $[\mathrm{P}<0.05]$. Sedation was found to be statistically significant for the first hour where patients of group RD were more sedated than group R . Changes in Systolic, Diastolic and Mean arterial Pressure and heart rate, were statistically insignificant in both groups. The incidence of Headache, nausea and vomiting and Dryness of mouth were not statistically significant in both the groups.

Our study Inaccordance with this study addition of dexmedetomidine In ropivacaine in TAP block helps achieve better analgesia and decreases the total dose of analgesics required post-operatively without any major side-effects.

No case reported of postoperative nausea and vomiting .In our study Dexmedetomidine used as adjuvant for increase onset, quality and duration of block. Dexmedetomidine hydrochloride, an imidazole compound is the pharmacologically active S-of medetomidine. Its specificity for the alpha- 2 receptor is 8 times that of clonidine, with an alpha-2 : alpha-1 binding affinity ratio of $1620: 1$ its effect are dose dependently reversed by administration of a selective alpha- 2 antagonist.

\section{Conclusion}

The present study“comparision between $0.2 \%$ Ropivacaine versus $0.2 \%$ Ropivacaine with Dexmedetomidine in USG Guided TAP block for post operative Analgesia in unilateral lower abdominal surgeries,, was conducted in the department of anaesthesiology, Swaroop Rani Nehru Haspital, MLN Medical college, Allahabad, U.P., India. Our study had 60 adult patients of more than 18 year and less than 60 years of age of ASA grade I and II of either sex divided into two groups of 30 each. They were given TAP block (USG guided) either Ropivacaine or Ropivacaine with Dexmeditomidine for unilateral 
lower abdominal surgeries Under General Anaesthesia .All patients were randomly allocated into two groups of 30 each.Group-R :USG guided TAP blok with $20 \mathrm{ml}$ Ropivacaine to that side .Group-D : USG guided TAP block with $20 \mathrm{ml}$ Ropivacaine with $0.5 \mu \mathrm{gm} / \mathrm{kg}$ Dexmeditomidine to that side.

With careful appraisal of the present study, following conclusion were drawn-

1) Both groups was comparable to each other with respect to age, sex, height and weight.

2) Time of onset of Analgesia in group- $R$ was significantly greater $(11.03 \pm 2.45 \mathrm{~min})$ as compared to group-D $(8.67 \pm 1.51 \mathrm{~min})$.

3) There was significant increased pulse rate in group-R after 12Hour of TAP block. In group-D, pulse rate not significan but decreased compare to $\mathrm{R}$.

4) There was no significant change in blood pressure in group-R. And group D.

5) Onset of analgesia(mints) Late in group $-\mathrm{R}(11.03 \pm 2.45)$ than group $\mathrm{D}(8.67 \pm 1.51)$ where $\mathrm{p}<0.05$ is more significant.

6) Duration of analgesia is more in Group D $(24.03 \pm 5.02)$ compare to $R(20.0 \pm 4.62)$ where $p<0.05$ more significant.

7) Mean VAS score was significantly more in group- $R$ (3.06 \pm 1.38$)$ as compared to group-RD (2.30 \pm 1.24$)$.

8) Quality of analgesia was better in group-D in comparison to group-R.

9) There was no side effect or complication in group-R. In group-D, bradycardia was noticed in 1 patients $(5 \%)$ After TAP block while No hypotension was noticed.

10) there was no sedation in Group- $R$ (1.16 \pm 0.37$)$ compare to Group-D (1.96 \pm 0.61$)$.

11) Time taken for first rescue analgesia was significantly greater in group- $R(3.13 \pm 0.86)$ in comparison to group- $\mathrm{D}(1.9 \pm 1.14)$.

We concluded from this study that although both Ropivacaine and Ropivacaine with Dexmeditomidine in USG guided TAP block are associated with minimum haemodynamic change, haemodynamic stability are better in Ropivacaine with Dexmeditomidine. TAP block is very good for postoperative analgesia and also in the term of side effects complication. Adition of adjuant as Dexameditomidine in Ropivacaine increase the onset quality and duration of analgesia compare to Ropivacaine alone. As there are few literature available on TAP block as a sole analgesic, further studies are required to substantiate the above finding.

\section{References}

[1]. KuppuvelumaniP,JjaradiH,DelikanA,Abdominal nerve blocked for post operative analgesia after caesarean section , Asia , Oceania JobstetGynaecol , 1993 ;

[2]. Song D, Grellich NB , white PF, watcha MF, Tongier WK, Recovesh profile and costs of Anaesthesia for out patients inguinal Herneorhaphy, AnesthAnalg 2000 , 91:876-81.

[3]. IASP Pain Terminology

[4]. B. D. O'Donnell, J. G. McDonnell, and A. J. McShane, "The TransversusAbdominis Plane (TAP) block in open retropubic prostatectomy," Regional Anesthesia and PainMedicine, vol. 31, no. 1, article 91, 2006

[5]. 5.J. Børglum, C. Maschmann, B. Belhage, and K. Jensen, "Ultrasound-guided bilateral dual transversusabdominis plane block: a new four-point approach," ActaAnaesthesiologicaScandinavica, vol. 55, no. 6, pp. 658-663, 2011.

[6]. A. Chetwood, S. Agrawal, D. Hrouda, and P. Doyle, "Laparoscopic assisted transversusabdominis plane block: a novel insertion technique during laparoscopic nephrectomy," Anaesthesia, vol. 66, no. 4, pp. 317-318, 2011.

[7]. N. Bharti, P. Kumar, I. Bala, and V. Gupta, "The efficacy of a novel approach to transversusabdominis plane block for postoperative analgesia after colorectal surgery," Anesthesia and Analgesia, vol. 112, no. 6, pp. 1504-1508, 2011

[8]. A. N. Rafi, "Abdominal field block: a new approach via the lumbar triangle," Anaesthesia, vol. 56, no. 10, pp. 1024-1026, 2001

[9]. R. J. Kearns and S. J. Young, "Transversusabdominis plane blocks; a national survey of techniques used by UK obstetric anaesthetists," International Journal of Obstetric Anesthesia, vol. 20, no. 1, pp. 103-104, 2011.

[10]. R. S. Atkinson, G. B. Rushman, and J. A. Lee, A Synopsis of Anaesthesia, Wright, Bristol, UK, 10th edition, 1987

[11]. J. G. McDonnell, B. D. O’Donnell, D Tuite, T. Farrell, and C. Power, "The Regional Abdominal Field Infiltration (R.A.F.I.) technique computerised tomographic and anatomical identification of a novel approach to the transversusabdominisneuro-vascular fascial plain," in Proceedings of the American Society of Anesthesiologists Annual Meeting, 2004, A-899. Abstract

[12]. J. G.McDonnell, B.D.O'Donnell, T. Farrell et al., "Transversusabdominis plane block: a cadaveric and radiological evaluation," Regional Anesthesia and Pain Medicine, vol. 32, no. 5, pp. 399-404, 2007.

[13]. J. G. McDonnell and J. G. Laffey, "Transversusabdominis plane block," Anesthesia and Analgesia, vol. 105, no. 3, article 883, 2007.

[14]. B. D. O'Donnell, J. G. McDonnell, and A. J. McShane, "The TransversusAbdominis Plane (TAP) block in open retropubic prostatectomy," Regional Anesthesia and PainMedicine, vol. 31, no. 1, article 91, 2006

[15]. P. Hebbard, Y. Fujiwara, Y. Shibata, and C. Royse, "Ultrasound-guided transversusabdominis plane (TAP) block," Anaesthesia and Intensive Care, vol. 35, no. 4, pp. 616-617, 2007.

[16]. McDonnell J, O’Donnell, Brian M, Curley G, Heffernan A, Power C, Laffey J. The Analgesic Efficacy of TransversusAbdominis Plane Block After Abdominal Surgery: A Prospective Randomized Controlled Trial. Anaesthesia and Analhesia 2007; $104: 193-7$.

[17]. Shibata et al Anesthesia \& Analgesia: September 2007 - Volume 105 - Issue 3 - p 883doi: 10.1213/01.ane.0000268541.83265.7d

[18]. McDonnell J, Curley G, Carney J, Benton A, Costello J, Maharaj C, Laffey J. The Analgesic Efficacy of TransversusAbdominis Plane Block After Cesarean Delivery: A Randomized Controlled Trial. Anesthesia and Analgesia 2008; 106: $186-91$. 
[19]. P. L. Petersen, O. Mathiesen, H. Torup, and J. B. Dahl, "The transversusabdominis plane block: a valuable option for postoperative Analgesia. A topical review” ActaAnaesthesiologicaScandinavica, vol. 54, no. 5, pp. 529-535, 2010

[20]. M. Singh, K. J. Chin, and V. Chan, "Ultrasound-guided transversusabdominis plane (TAP) block: a useful adjunct in the management of postoperative respiratory failure," Journal of Clinical Anesthesia, vol. 23, no. 4, pp. 303-306, 2011.

[21]. P. Hebbard, "Subcostal transversusabdominis plane block under ultrasound guidance," Anesthesia and Analgesia, vol. 106, no. 2, pp. 674-675, 2008.

[22]. E. Allcock, E. Spencer, R. Frazer, G. Applegate, and C. Buckenmaier III, "Continuous transversusabdominis plane (TAP) block catheters in a combat surgical environment," Pain Medicine, vol. 11, no. 9, pp. 1426-1429, 2010.

[23]. K. O'Connor and C. Renfrew, "Subcostal transversusabdominis plane block," Anaesthesia, vol. 65, no. 1, pp. 91-92, 2010.

[24]. M. Forero, V. M. Neira, A. J. Heikkila, and J. E. Paul, "Continuous lumbar transversusabdominis plane block may spread to supraumbilical dermatome," Canadian Journal of Anesthesia, vol. 58, no. 10, pp. 948-951, 2011.

[25]. Jankovic Z, Ahmad N, Ravishankar N, Archer F 2008

[26]. Transversusabdominis plane block: how safe is it? AnesthAnalg 107: 1758-1759

[27]. Periodicumbiologorum UDC 57:61 VOL. 111, No 2, 203-208, 2009

[28]. The Iraqi Postgraduate Medical Journal vol.11, supplement,2012

[29]. Canadian Journal of Anesthesia March 2013, Volume 60, Issue 3, pp 299-303 Date: 20 Dec 2012

[30]. Journal of Anaesthesiology Clinical Pharmacology | October-December 2013 | Vol $29 \mid$ Issue 4

[31]. Journal of Anaesthesiology Clinical Pharmacology Year : 2014 | Volume : 30 | Issue : 3 | Page : 391-396

[32]. Hadzic A. Textbook of regional anaesthesia and acute pain management. 1st ed. New York. McGraw-Hill. 2007: 8, 691.

[33]. Farooq M, Carey M. A Case of Liver Trauma With a Blunt Regional Anesthesia Needle While Performing TransversusAbdominis Plane Block Regional Anesthesia and Pain Medicine 2008; 33: 274-5.

[34]. The New York School Of Regional Anesthesia May 2009 Volume 12 TransversusAbdominis Plane (Tap) Block

[35]. Casati et al. Cardiac performance during unilateral lumbar spinal block after crystalloid preload. Can J Anaesth 1997; 44: 623-8.

[36]. Casati A, Fanelli G, Aldegheri G, et al. Frequency of hypotension during conventional or asymmetric hyperbaric spinal block. RegAnesth Pain Med 1999; 24(3): 214-9

[37]. Racle JP, Benkhadra A, Poy JY, Gleizal B. Spinal analgesia with hyperbaric bupivacaine: influence of age. Br J Anaesth 1988; 60: 508-14.

[38]. Veering BT, Burm AGL, Spierdijk J. Spinal anesthesia with hyperbaric bupivacaine: effects of age on neural blockade and pharmacokinetics. Br J Anaesth 1988; 60: 187-94

[39]. Veering BT, Burm AGL, Vletter AA, Van den Hoeven RAM, Spierdijk J. The effect of age on systemic absorption and systemic disposition of bupivacaine after subarachnoid administration. Anesthesiology 1991; 74: 250-7

[40]. Carpenter RL, Caplan RA, Brown DL, Stephenson C, Wu R. incidence and risk factors for side effects of spinal anesthesia. Aesthesiology 1992; 76: 906-16

[41]. Chamberlain DP, Chamberlain BDL. Changes in the skin temperature of the trunk and their relationship to sympathetic blockade during spinal anesthesia. Anesthesiology 1986; 65: 139-43

[42]. Green NM, The area of differential block during spinal anesthesia with hyperbaric tetracaine. Anesthesiology 1958; $19: 4 \$-50$

[43]. Chamberlain DP, Chamberlain SD. Changes in the skin temperature of the trunk and their relationship to sympathetic blockade during spinal anesthesia. Anesthesiology 1986; 65: 139-43.

[44]. Ward RJ, Bonica .JJ, Frend PG. at at. Epidural and subarachnoid anesthesia cardiovascular and respiratory effects, j. Am. Mod. Assoc, 1965; $191-275$,

[45]. Casati A, Fanelli 0, Beccarla P, et at. Block distribution and cardiovascular effects of unilateral spinal anesthesia by $0.5 \%$ hyperbaric bupivacain. a clinical comparison with bilateral spinal block. Minerva - Anesthesiology. 1998; 64 : 307-12, JPMA52:66,2002

[47]. PeriodicumBiologorum Vol. 113, No 3, 349-353, 2011

[48]. Saudi Journal Of Anaesthesia Year: 2014 | Volume : 8 | Issue : 3 | Page : 384-387

[49]. Journal of International Medical Research (October 2013) vol. 415 1639-1647

[50]. Kutiyala G, Chaudhary G. Ropivacaine: A review of its pharmacology andclinical use. Indian J Anaesth 2011;55:104-110.50. McClure JH. Ropivacaine. BJA 1996;76:300-7.

[51]. Simpson D, Curran MP, Oldfield V, Keating GM. Ropivacaine A review of itsuse in regional anaesthesia and acute pain management. Drugs 2005;65(18):2675-717.

[52]. Abramov D, Nogid B, Nogid A. Drug forecast. PandT 2005 Mar;30(3):158.

[53]. Haselman A M. Dexmedetomidine: A useful adjunct to consider in some highrisk situation. AANA Journal 2008 Oct;76(5).

[54]. Scheinin H, Aantaa R, Anttila M, Hakola P, Helminen A, Karhuvaara S.Reversal of the sedative and sympatholytic effects of dexmedetomidine withspecific alpha-2 receptor antagonist atipamazole; pharmacodynamioc andkinetic study in healthy volunteers. Anaesthesiology 1998;89:574-84.

[55]. Ma D, Hossain M, Raja Kumara Swamy N. Dexmedetomidine produces itsneuroprotective effect via the alpha-2 receptor subtype. Eu J Pharmacol 2004;502;87-97.

[56]. Fagerholm V, Scheinin M, Haaparanta M. Alpha -2 adrenoceptor antagonismincreases insulin secretion and synergistically augments the insulinotropiceffect of glibenclamide in mice. Br J Pharmacol 2008;154;1287-96.

[57]. Moura E, Afonso J, Hein L. Alpha-2 adrenoceptor subtypes involved in theregulation of catecholamine release from the adrenal medulla of mice. Br JPharmacol 2006;149(8);1049-58.

[58]. Ralph Getler, Clieghton H Brown, Mitchel H, Silvius N. Dexmedetomidine: anovel sedative analgesic agent. Baylor University Medical Centre Proceedings.2001;14(1).

[59]. Panzer O, Moitra V, Roberet N Sladen. Pharmacology of sedative-analgesicagents - Dexmedetomidine, remifentanil, ketamine, volatile anaestheitcs andthe role of Mu antagonists. Critical Clin 2009;25:451-69.

[60]. Aho M, Erkola O, Kallio A, Scheinin H, Korttila K. Comparison ofdexmedetomidine and midazolam sedation and antagonism ofdexmedetomidine with atipamazole. J ClinAnaesth; 1993;5:194-203.

[61]. 61. Arian SR, Ebert TJ. The efficacy, side effects and recovery characteristics of

[62]. dexmedetomidine versus propofol when used for intraoperative sedation.

[63]. AnaesthAnalg 2002;98;153-8.

[64]. Arian SR, Ruchlow RM, Uhrich TD, Ebert TJ. Efficacy of Dexmedetomidine versus morphine for post-operative analgesia after major in-patient surgery. AnaesthAnalg 2004;98;153-8.

[65]. Bloor BC, Ward DS, Belleville JP, Maze M. Effects of intravenousdexmedetomidine in humans. II Haemodynamic changes. Anaesthesiology1992;77:1134-42 
[66]. Hall JE, Jurich TD, Barney JA, Arian SR, Ebert TJ. Sedative amnestic, andanalgesic properties of small dose of dexmedetomidine infusions. AnaesthAnalg 2000;90;699-705.

[67]. Maze M, Virtanen R, Daunt D, Stephen JM, Stover P, Feldman D. Effects ofdexmedetomidine, a novel imidazole sedative anaesthetic agent on adrenalsteriodogenesis; in vivo and in vitro studies. AnaesthAnalg 1991;73:204-8.

[68]. Ralph Getler, Clieghton H Brown, Mitchel H, Silvius N. Dexmedetomidine: anovel sedative analgesic agent. Baylor University Medical Centre Proceedings.2001;14(1).

[69]. Vilo S, Rantiainen P, Kaistik, Auntaa R, Scheinin M, Manner T, et al.Pharmacokinetics of intravenous dexmedetomidine in children under 11 year ofage. Br J Anaesth 2008;100:697-700.

[70]. El-Hennawy AM, Abd-Elwahab. Addition of clonidine or dexmedetomidine tobupivacaine prolongs caudal analgesia in children. Br J Anaesth 2009;103;268-74.

[71]. Siobal SM, Kullet HR, Kivett AV, Tang FJ. Use of dexmedetomidine tofacilitate extubation in surgical intensive care unit patients who failed previousweaning attempts following prolonged mechanical ventilational; a pilot study.Respir Care 2006;57:492-6.

[72]. Precedex (Dexmedetomidine) Package Insert. Abott Park II; AbottLaboratories; 2004

[73]. k.o.connor et al.2010 'subcostal transversusabdominis plane block' Anesthesia,vol 65,no./pp.91-92,2016

[74]. De-olivera et al (2014):transversusabdominis plane block, To Ameliorate post operative pain outcomes after laparoscopic surgery; A Meta-analsis of Randamizedcantrolltrials.Anesthesia\& Aalgesia,2014;118,454-463.

[75]. Venkatraman et al(2016)https//dx.doi.org/10.2147/LRS93673

[76]. IOSR--.jaurnal of Dental and Medical sciences (IOSR-JDMS).e-155N;2279-0853,P-155N,2279-0861 volum 15,155ve 2ver,v( Feb2016)pp 122-125 www.iosrjournals.org. 